\title{
Epidemiological and molecular biological studies of multi-resistant methicillin-susceptible
}

Staphylococcus aureus

\author{
Maria Lindqvist
}

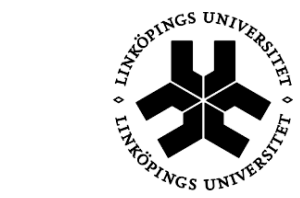

\section{Linköping University}

FACULTY OF HEALTH SCIENCES

Clinical Microbiology

Department of Clinical and Experimental Medicine

Faculty of Health Sciences

Linköping University, Sweden

Linköping 2014 
(C) Maria Lindqvist

All previously published papers reprinted with permission from the publishers

ISBN 978-91-7519-444-8

ISSN 0345-0082

Printed by LiU-tryck, Linköping, Sweden, 2014 
To my beloved son Carl.

Thank you for reminding me of what life is really about $\uparrow$ 



\section{Abstract}

Antibiotic resistance is increasingly recognised as a major problem and threat. During the last decades Gram-positive bacteria in general, and methicillin-resistant Staphylococcus aureus (MRSA) in particular, have been in focus both concerning matters of antibiotic resistance and as pathogens causing health care-associated (nosocomial) infections. In contrast to MRSA, studies on clonal distribution of methicillin-susceptible $S$. aureus (MSSA) are scarce. However, interest in MSSA has increased since it was shown that MRSA emerges from susceptible backgrounds by acquisition of a staphylococcal cassette chromosome element, carrying the mecA gene encoding methicillin-resistance (SCCmec).

In an outbreak investigation of MRSA in Östergötland County, Sweden, in 2005, a high incidence of MSSA isolates with concomitant resistance to erythromycin, clindamycin and tobramycin (ECT-R) was detected. Analysis showed that $91 \%$ of the investigated isolates were genetically related (clonal). The ECT-R clone was divided into four different but closely related patterns with pulsed-field gel electrophoresis (PFGE), and was designated spa type t002. Whole genome sequencing revealed that the ECT-R clone carried a pseudo-SCC element estimated to be $12 \mathrm{~kb}$ in size, showing a resemblance of more than $99 \%$ with the SCCmec type II element of MRSA strain N315 (New York/Japan clone). This suggested a probable derivation from a highly successful MRSA strain, which had partially excised its SCCmec. The clonal outbreak was concentrated in eight hospital departments and two primary care centres, all located in the city of Linköping. Despite a high exchange of patients with the hospitals in the neighbouring counties in southeast Sweden (Jönköping- and Kalmar County), the ECT-R clone seemed to be limited to Östergötland County. However, a tobramycin-resistant clone predominated by isolates of spa type t084 was found in all three counties in southeast Sweden, and in particular among newborns, suggesting inter-hospital transmission.

The ECT-R clone has survived as an abundant MSSA clone for a decade in Östergötland County, which indicates an insufficiency in the maintenance of basic hygiene guidelines, and that the clone probably possesses mechanisms of virulence and transmission that are yet to be discovered. 


\section{Sammanfattning på svenska}

Antibiotikaresistens är ett ökande allvarligt problem som med tiden fått allt mer uppmärksamhet. Under de senaste årtiondena har Grampositiva bakterier, framför allt meticillin-resistenta Staphylococcus aureus (MRSA), varit ett dominerande resistensproblem och orsak till vårdrelaterade infektioner (VRI). Till skillnad mot MRSA finns få studier som beskriver klonal utbredning av meticillin-känsliga S. aureus (MSSA). Dock har intresset för MSSA ökat genom kunskapen om att MRSA härstammar från MSSA genom förvärv av ett "staphylococcal cassette chromosome element" med mecA genen som kodar för meticillinresistens ( $\mathrm{SCCmec})$.

I samband med ett utbrott av MRSA i Östergötland, Sverige, år 2005 upptäcktes en hög förekomst av MSSA isolat med samtidig resistens mot erytromycin, klindamycin och tobramycin (ECT-R). Analys av dessa isolat visade att $91 \%$ var genetiskt besläktade (klonala). ECT-R klonen delades in i fyra olika men nära besläktade mönster med pulsfältgelelektrofores (PFGE) och tillhörde spa typ t002. Sekvensering av hela genomet hos ett representativt isolat visade att klonen bar på ett $12 \mathrm{~kb}$ stort pseudo-SCCmec element, som till mer än 99 \% liknade SCCmec typ II elementet hos MRSA stammen N315 (New York/Japan klonen). Detta indikerade att ECT-R klonen sannolikt härstammar från en framgångsrik MRSA stam som delvis förlorat sitt SCCmec element. Det klonala utbrottet var koncentrerat till åtta vårdavdelningar på Linköpings Universitetssjukhus samt två vårdcentraler i Linköping. Trots ett stort utbyte av patienter med sjukhusen i de andra länen $\mathrm{i}$ sydöstra sjukvårdsregionen (Jönköpings- och Kalmar län) var ECT-R klonen begränsad till Östergötland. Däremot påträffades en tobramycin-resistent klon med spa typ t084 i samtliga tre län, och i synnerlighet ibland nyfödda barn, vilket indikerade en smittspridning mellan sjukhusen.

ECT-R klonen har överlevt som en framgångsrik MSSA klon i Östergötland i ett årtionde. Detta tyder på brister i upprätthållandet av basala hygienregler, och att klonen sannolikt har egenskaper för virulens och spridning som återstår att påvisa. 


\section{List of papers}

\section{Paper I}

Lindqvist M, Isaksson B, Samuelsson A, Nilsson LE, Hällgren A. A clonal outbreak of methicillin-susceptible Staphylococcus aureus with concomitant resistance to erythromycin, clindamycin and tobramycin in a Swedish county. Scand J Infect Dis. 2009; 41: p. 324-33.

\section{Paper II}

Lindqvist M, Isaksson B, Grub C, Jonassen TØ, Hällgren A. Detection and characterisation of SCCmec remnants in multi-resistant methicillin-susceptible Staphylococcus aureus causing a clonal outbreak in a Swedish county. Eur J Clin Microbiol Infect Dis. 2012; 31: p. 141-7.

\section{Paper III}

Lindqvist M, Isaksson B, Nilsson LE, Wistedt A, Swanberg J, Skov R, Rhod Larsen A, Larsen J, Petersen A, Hällgren A. Genetic relatedness of multi-resistant methicillinsusceptible Staphylococcus aureus in southeast Sweden. Manuscript. 



\section{Abbreviations}

AAC

acetyltransferases

ACMEs

arginine catabolic mobile elements

$a g r$

accessory gene regulator

AMEs

aminoglycoside-modifying enzymes

ANT

nucleotidyltransferases

APH

phosphotransferases

bp

base pair

CA

community-associated

CC

clonal complex

ccr

cassette chromosome recombinase

CDC

Centers for Disease Control and Prevention

CHEF

contour-clamped homogeneous electric field

CLSI

American Clinical and Laboratory Standards Institute

$d c s$

downstream conserved segment

DNA

deoxyribonucleic acid

dNTPs

deoxyribonucleotide triphosphates

ECDC

European Centre for Disease Prevention and Control

ECT-R

erythromycin-, clindamycin- and tobramycin-resistance

Etest

Epsilon test

EUCAST

European Committee on Antimicrobial Susceptibility Testing

GISA

glycopeptide intermediate $S$. aureus

HA

health care-associated 


\begin{tabular}{|c|c|}
\hline hGISA & heterogeneous glycopeptide intermediate $S$. aureus \\
\hline I & intermediate \\
\hline ISS & integration site sequence \\
\hline J-regions & joining regions \\
\hline $\mathrm{kb}$ & kilo base pair \\
\hline LA & livestock-associated \\
\hline MDR & multidrug-resistance \\
\hline MGEs & mobile genetic elements \\
\hline MIC & minimum inhibitory concentration \\
\hline $\mathrm{MLS}_{\mathrm{B}}$ & macrolide, lincosamide and streptogramine B \\
\hline MLST & multi-locus sequence typing \\
\hline MREJ & SCCmec right extremity junction \\
\hline mRNA & messenger ribonucleic acid \\
\hline MRSA & methicillin-resistant $S$. aureus \\
\hline MSCRAMMs & $\begin{array}{l}\text { microbial surface components recognizing adhesive matrix } \\
\text { molecules }\end{array}$ \\
\hline MSSA & methicillin-susceptible S. aureus \\
\hline ND & not defined \\
\hline ORF & open reading frame \\
\hline PBP & penicillin-binding protein \\
\hline PCR & polymerase chain reaction \\
\hline PDR & pandrug-resistance \\
\hline PFGE & pulsed-field gel electrophoresis \\
\hline
\end{tabular}




\begin{tabular}{|c|c|}
\hline PVL & Panton-Valentine leukocidine \\
\hline $\mathrm{R}$ & resistant \\
\hline RNA & ribonucleic acid \\
\hline rRNA & ribosomal ribonucleic acid \\
\hline S & susceptible \\
\hline SCCmec & staphylococcal cassette chromosome mec \\
\hline SCVs & small colony variants \\
\hline SMI & Swedish Institute for Infectious Disease Control \\
\hline spa & staphylococcal protein A \\
\hline SRGA & Swedish Reference Group for Antibiotics \\
\hline SSTIs & skin- and soft tissue infections \\
\hline ST & sequence type \\
\hline tRNA & transfer ribonucleic acid \\
\hline TSS & toxic shock syndrome \\
\hline XDR & extensive drug-resistance \\
\hline
\end{tabular}





\section{Table of contents}

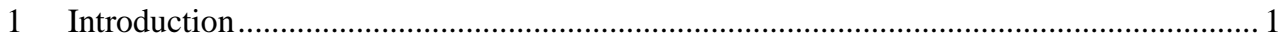

$1.1 \quad$ Staphylococcus aureus .................................................................................... 1

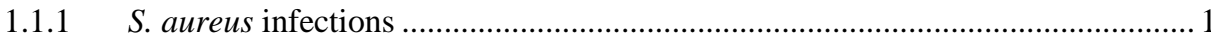

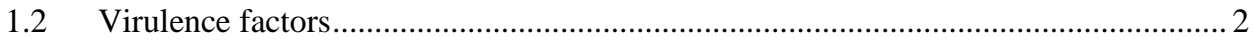

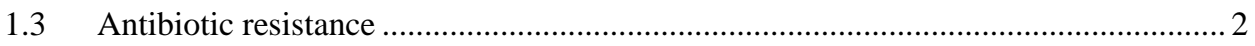

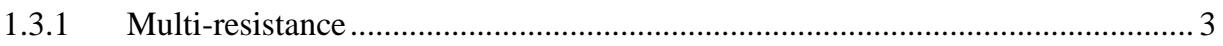

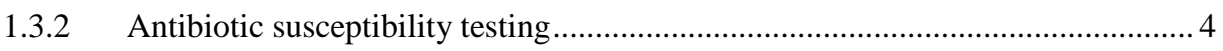

1.4 Antibiotics for treatment of $S$. aureus infections.................................................. 4

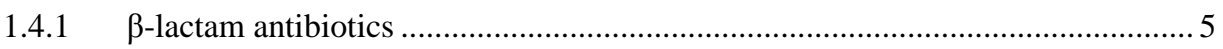

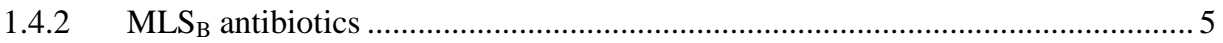

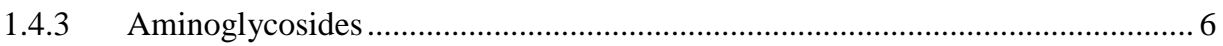

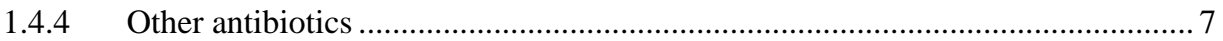

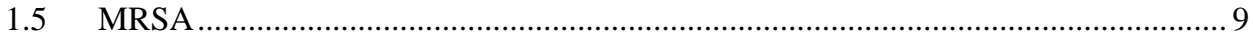

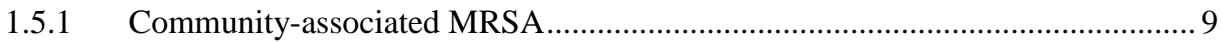

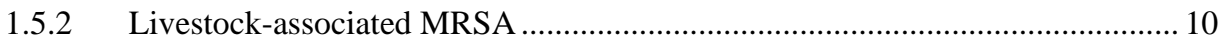

1.5.3 mec

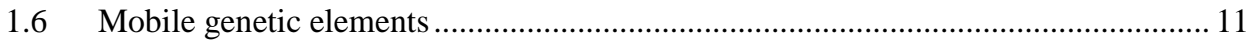

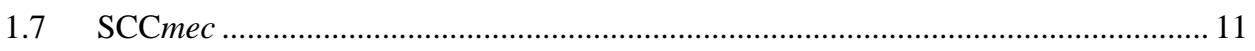

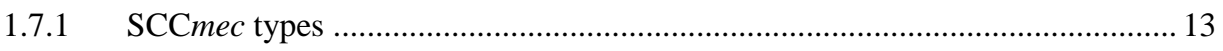

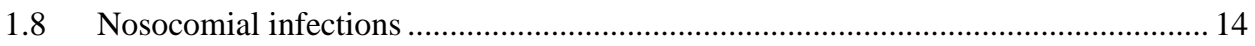

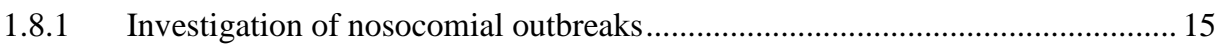

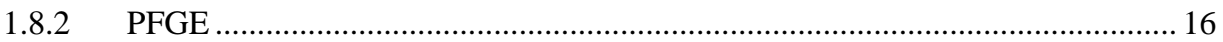

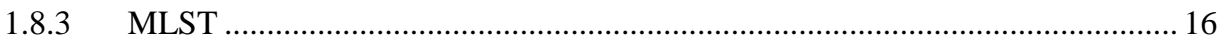

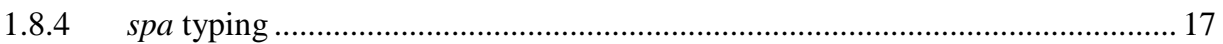

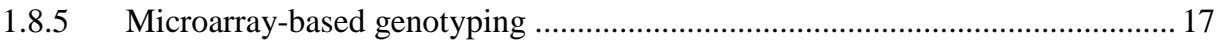


1.8.6 Comparison of molecular genotyping methods

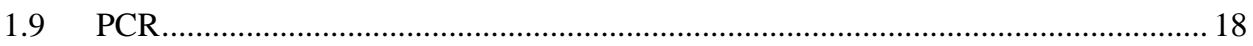

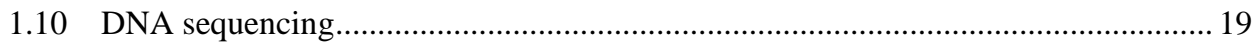

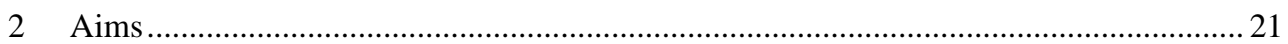

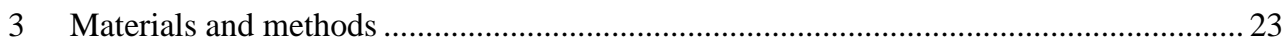

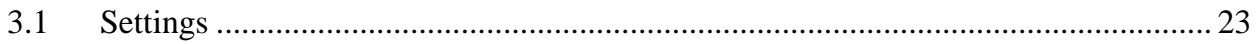

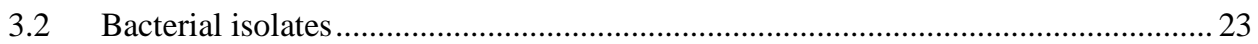

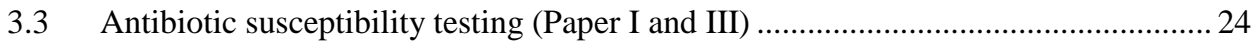

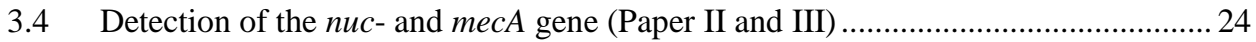

3.5 Detection of antibiotic resistance genes (Paper II and III) .................................... 25

3.6 Detection of virulence genes (Paper I and III) ................................................... 26

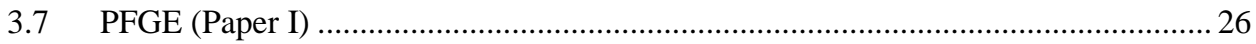

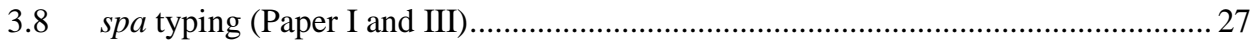

3.9 Microarray-based genotyping (Paper III) ....................................................... 27

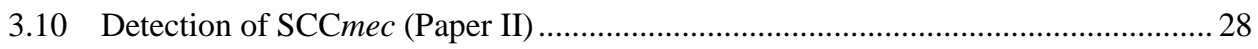

3.10.1 Analysis of the SCCmec right extremity junction (Paper II and III) .................28

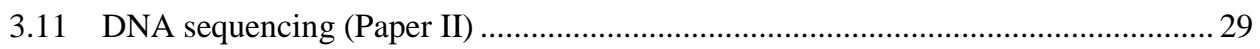

3.12 Epidemiological investigation of nosocomial transmission (Paper I and III) .......... 29

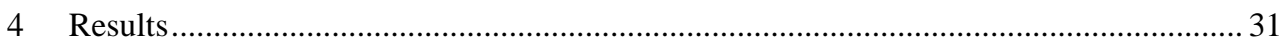

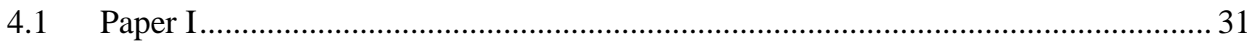

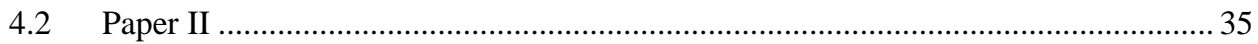

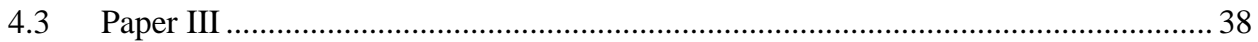

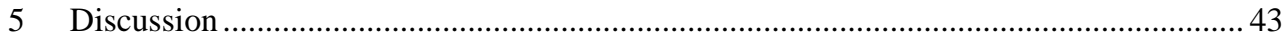

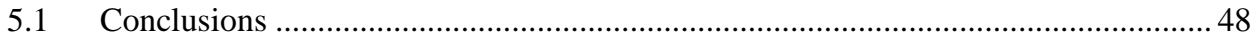

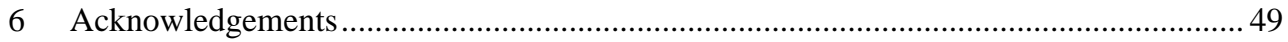

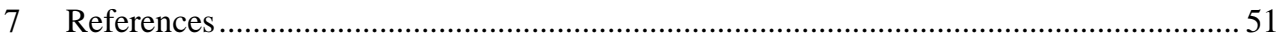




\section{Introduction}

\subsection{Staphylococcus aureus}

The genus Staphylococcus includes at least 40 species and sub-species [1], of which several are capable of colonising humans. Staphylococci are Gram-positive bacteria, which are facultative anaerobes. They are approximately $1 \mu \mathrm{m}$ in size and grow in pigmented yellow or white colonies. They may occur singly or grouped in pairs, short chains or grape-like clusters. Staphylococci are catalase-positive, oxidase-negative and have different proteins, teikon acids and polysaccharides on their cell surface, which are important for the structure. Depending on their ability to coagulate plasma, staphylococci are classified as either coagulase-positive or coagulase-negative [2].

Staphylococcus aureus is the clinically most important species among the staphylococci, and can be distinguished from the other members by its ability to produce coagulase and DNase [3]. It is an opportunistic pathogen, which is frequently part of the human microflora, causing disease when the immune system becomes compromised [4]. S. aureus is normally found on the skin and mucous membranes, and the most frequent carriage site is the anterior nares of the nose. Other sites include the axillae, gastrointestinal tract, perineum, pharynx and vagina [5]. Nasal $S$. aureus carriage can be categorised into persistent carriers, intermittent carriers and non-carriers. Longitudinal studies have shown that approximately $20 \%$ of the population carry $S$. aureus persistently. Persistent carriers have a higher density of S. aureus, which may explain their increased risk for $S$. aureus infections. Variations among colonising strains are higher for intermittent carriers [5-8].

\subsubsection{S. aureus infections}

S. aureus is only able to invade a host via broken skin or mucous membranes. Once invaded, it has various ways to avoid the immune defence, and to cause tissue damage and infection. Generally, S. aureus can cause three types of infection: (i) superficial lesions such as wound infections; (ii) life-threatening conditions such as bacteraemia, brain abscesses, endocarditis, meningitis, osteomyelitis and pneumonia; and (iii) toxinoses such as food poisoning, scalded skin syndrome and toxic shock syndrome (TSS) [9]. Most infections occur in healthy individuals, but underlying illness and certain diseases may increase the risk of infection. A 
significantly higher $S$. aureus carriage rate appears in patients with insulin-dependent diabetes mellitus, patients on dialysis, HIV- or AIDS patients, patients with S. aureus skin infections and intravenous drug addicts [6]. While minor infections caused by $S$. aureus are normally harmless, antibiotic treatment is always necessary in the case of serious infections [3].

\subsection{Virulence factors}

To cause infection in a host, a bacterium uses its virulence factors in order to: (i) promote adherence and invasion; (ii) contribute to immune evasion; and (iii) cause damage either by direct toxicity, or indirectly by inducing an inflammatory response [3].

Staphylococcal virulence factors may have several functions in pathogenesis, and multiple virulence factors may perform the same function. S. aureus has numerous surface proteins, called microbial surface components. These recognize adhesive matrix molecules (MSCRAMMs), which mediate adherence to host tissues. S. aureus is able to survive and multiply inside a host in various ways. It can form biofilms or small colony variants (SCVs), invade and survive inside epithelial cells, produce antiphagocytic microcapsules, and prevent opsonisation by the binding of protein A to the Fc portion of immunoglobin. Surface proteins are established in an early stage of the bacterial growth, whereas secretion of enzymes and toxins is produced when the growth starts to decline as a result of malnutrition. The enzymes and toxins can act together or alone, and the expression is coordinated by regulatory systems, such as the $\operatorname{agr}$ (accessory gene regulator), which induce the production of various proteins during different bacterial growth phases. Examples of toxins produced by $S$. aureus are enterotoxins, exfoliate toxins, hemolysins, leukocidins and TSS toxin [10-11]. PantonValentine leukocidine (PVL) is an exotoxin belonging to the pore-forming toxin family, and is encoded by two co-transcribed genes designated $l u k F-P V$ and $l u k S-P V$. It has been shown to induce lysis of human leukocytes, which causes skin and soft-tissue infections (SSTIs) and severe necrotising pneumonia in young and otherwise healthy individuals [12-15].

\subsection{Antibiotic resistance}

Generally, antibiotics can be classified into four groups: (i) cell wall synthesis inhibitors; (ii) protein synthesis inhibitors; (iii) nuclein acid synthesis inhibitors; and (iv) antibiotics 
affecting membrane permeability. Antibiotics are either bacteriostatic or bactericidal. A bacteriostatic antibiotic stops the bacterium from reproducing by interfering with the bacterial cellular metabolism. When the bacteriostat is removed, the bacterium usually starts to grow again. In contrast, a bactericidal antibiotic kills the bacterium [16].

Antibiotic resistance can be divided into intrinsic- and acquired resistance. Intrinsic resistance is the natural resistance possessed by most isolates of a bacterial species, and is due to the isolate's inherent structural or functional characteristics. Acquired resistance is when a bacterial species becomes resistant to an antibiotic to which it was previously susceptible. This may be due to mutations of genes involved in normal physiological processes and cellular structures, acquired mobile resistance genes or a combination of both. Mechanisms of resistance include: (i) alternation of the antibiotic target; (ii) reduced uptake; (iii) active efflux; and (iv) enzymatic inactivation [17].

The most important way to prevent antibiotic resistance is to minimise unnecessary prescribing of antibiotics. This occurs when antibiotics are over-used as a result of prescribing antibiotics for viral illnesses (which cannot be treated with antibiotics), or when antibiotics are wrongly used when prescribed for conditions that do not require them. The causative pathogen must be identified so that the appropriate antibiotic can be used, instead of relying on a broad-spectrum antibiotic. Furthermore, practising good hygiene and using appropriate infection control procedures are important [18-20].

\subsubsection{Multi-resistance}

The emergence of multi-resistance to antibiotics among nosocomial pathogens has become a significant public health threat as there are few, or sometimes no, effective antibiotics available for treatment of infections caused by these bacteria. Until very recently, no standardised definitions with which to describe and classify multi-resistant bacteria have existed. Such definitions enable the reliable collection of epidemiological surveillance data, and subsequent comparison between health care facilities and countries.

Following an initiative by the European Centre for Disease Prevention and Control (ECDC) and the Centers for Disease Control and Prevention (CDC), a standardised international terminology was created to describe resistance profiles in bacteria often responsible for nosocomial infections and prone to multi-resistance. Epidemiologically significant antibiotic 
groups were constructed for each bacterium. Multidrug-resistance (MDR) was defined as nonsusceptibility to at least one antibiotic in three or more antibiotic groups. Extensive drugresistance (XDR) was defined as non-susceptibility to at least one antibiotic in all except two or fewer groups, and pandrug-resistance (PDR) was defined as non-susceptibility to all antibiotics in all groups. Thus, a bacterial isolate classified as XDR is also MDR, and a XDR isolate can be further classified as PDR [21].

In this thesis, multi-resistance is defined as resistance to two or more classes of non- $\beta$ lactam antibiotics. Although set prior to the publication of the above described standardised definitions, this is in accordance with the proposed definition for MDR.

\subsubsection{Antibiotic susceptibility testing}

The minimal inhibitory concentration (MIC), measured in $\mathrm{mg} / \mathrm{L}$, is the lowest concentration of an antibiotic needed to inhibit bacterial growth. Antibiotic susceptibility is interpreted as susceptible (S), intermediate (I) or resistant (R) [22]. In Sweden, antibiotic susceptibility testing is performed according to the Swedish Reference Group of Antibiotics (SRGA) and the subcommittee on methodology (NordicAST), which uses the same guidelines and breakpoints as the European Committee on Antimicrobial Susceptibility Testing (EUCAST). A corresponding committee is the American Clinical and Laboratory Standards Institute (CLSI).

There are different methods for susceptibility testing. The Epsilon test (Etest) is a MIC determination method where a strip containing an antibiotic gradient is used. The agar disk diffusion method is based on bacterial growth on an agar plate with a small paper disk impregnated with a specific concentration of an antibiotic placed on the surface of the plate. [22].

\subsection{Antibiotics for treatment of $S$. aureus infections}

There are a wide range of antibiotics available for treatment of $S$. aureus infections. $\beta$-lactam antibiotics are generally the most effective and appropriate choice for treatment of infections caused by susceptible $S$. aureus. Patients who are allergic to $\beta$-lactams or carry resistant $S$. aureus strains are treated with other groups of antibiotics [23]. The glycopeptide vancomycin 
has been considered the only remaining option of treatment of multi-resistant health careassociated (HA) methicillin-resistant $S$. aureus (MRSA). However, the increased usage has resulted in selection for resistant strains, although these are still rare [9, 23]. Linezolid (oxazolidinone) is another treatment option. Unlike other newer antibiotics for MRSA infections, linezolid can be given orally as well as intravenously, making it suitable for outpatient use. It has been shown that treatment with linezolid is more effective than vancomycin in some patients, for example those with pneumonia and SSTIs caused by MRSA [24-25]. However, negative side effects occur with both of these antibiotics, which limit their use.

\subsection{1 $\beta$-lactam antibiotics}

Before antibiotics came into use, infections caused by $S$. aureus had high mortality rates. One of the most important groups of antibiotics, both historically and medically, is the $\beta$-lactam group. The $\beta$-lactam antibiotics include the penicillins, cephalosporins, carbapenems and monobactams, which all carry a $\beta$-lactam ring. They are bactericidal and inhibit the cell wall synthesis by binding to the penicillin binding proteins (PBPs) of the bacterium, resulting in failure of the transpeptidation of peptidoglycan [26].

Resistance is mainly based on altered PBPs with low affinity for $\beta$-lactam antibiotics, or by production of $\beta$-lactamase enzymes, which hydrolyse the $\beta$-lactam ring and thereby deactivate the antibiotic. Today more than $90 \%$ of clinical $S$. aureus isolates produce $\beta$-lactamases, with primary affinity to penicillins [27]. The $\beta$-lactamases are encoded by the blaZ gene, which expression is regulated by its regulatory genes blaRl (a signal transducer) and blaI (a repressor) [27-28]. To control the increasing number of $\beta$-lactamase producing $S$. aureus, semi-synthetic penicillins (methicillin and oxacillin) have been produced [29].

\subsection{2 $\mathrm{MLS}_{\mathrm{B}}$ antibiotics}

The $\mathrm{MLS}_{\mathrm{B}}$ antibiotics include the macrolides (such as erythromycin), lincosamides (such as clindamycin) and streptogramin B. These are protein synthesis inhibitors and act by binding to the $50 \mathrm{~S}$ ribosomal subunit, thereby inhibiting the peptidyl transferase reaction. They are 
bacteriostatic for the staphylococci, unless combined with agents such as streptogramin A [29].

Resistance to $\mathrm{MLS}_{\mathrm{B}}$ antibiotics in staphylococci is mainly based on the modification of the bacterial target site by dimethylation of an adenine residue in the $23 \mathrm{~S}$ ribosomal ribonucleic acid (rRNA), which totally eliminates the binding of the antibiotic to its target. There are four major types of methylase genes: ermA, ermB, ermC and ermF (erythromycin ribosome methylation), with ermA and ermC being the most frequent in staphylococci. Expression of $\mathrm{MLS}_{\mathrm{B}}$ resistance is either inducible or constitutive. In inducible expression, the bacterium produces inactive messenger $(\mathrm{m})$ RNA, which is unable to encode methylase. The mRNA becomes active only in the presence of an inducer. By contrast, in constitutive expression, active methylase mRNA is produced in the absence of an inducer [30]. Only erythromycin and other 14- and 15-membered macrolides are capable of acting as inducers. Thus, when the expression is inducible, the bacterium becomes resistant only to the present inducer, whereas it becomes resistant to all MLS $\mathrm{B}_{\mathrm{B}}$ antibiotics when the expression is constitutive [31]. Resistance can also occur by active efflux or enzymatic inactivation [29-30].

\subsubsection{Aminoglycosides}

The aminoglycosides include amikacin, gentamicin, netilmicin and tobramycin. Other aminoglycosides that are not approved in Sweden because of their toxicity are arbekacin, debekacin, kanamycin and streptomycin. They are bactericidal and inhibit the protein synthesis by binding irreversibly to the $30 \mathrm{~S}$ subunit of the bacterial ribosome. The result is that aminoacyl-tranport (t) RNAs are unable to bind productively to the acceptor-site, preventing elongation of the peptide chain [29]. Aminoglycosides can synergise with other antibiotics, resulting in an increased uptake of the aminoglycoside into the bacterial cell, which in turn allows more effective killing of the bacterium [32].

The most common mechanism of resistance to aminoglycosides in staphylococci is based on inactivation by specific aminoglycoside-modifying enzymes (AMEs). There are three different types of AMEs: (i) acetyltransferases (AAC); (ii) nucleotidyltransferases (ANT); and (iii) phosphotransferases (APH), which act on different aminoglycosides [33]. The clinically most important enzyme is $\mathrm{AAC}\left(6^{\prime}\right)-\mathrm{APH}\left(2^{\prime \prime}\right)$, which confers resistance to practically all 
aminoglycosides available, except streptomycin [29]. Other resistance-mechanisms include alternation in the ribosomal binding of the antibiotic, reduced uptake and active efflux [33].

\subsubsection{Other antibiotics}

A number of other antibiotics are used for the treatment of $S$. aureus infections. Other antibiotics included for antibiotic susceptibility testing in this thesis are presented and described in Table 1 [34-35]. 
Table 1: Description of other antibiotics included for antibiotic susceptibility testing in this thesis.

\begin{tabular}{|c|c|c|c|}
\hline $\begin{array}{l}\text { Antibiotic } \\
\text { group }\end{array}$ & $\begin{array}{l}\text { Antibacterial } \\
\text { target }\end{array}$ & $\begin{array}{l}\text { Mechanism of } \\
\text { action }\end{array}$ & $\begin{array}{l}\text { Mechanism of } \\
\text { resistance }\end{array}$ \\
\hline Fusidic acid & $\begin{array}{l}\text { Protein } \\
\text { synthesis }\end{array}$ & $\begin{array}{l}\text { Inhibiting the elongation } \\
\text { factor } \mathrm{G} \text {. }\end{array}$ & $\begin{array}{l}\text { 1) Mutations in the fusA gene, } \\
\text { encoding the elongation factor } \\
\text { G. } \\
\text { 2) Acquisition of the fusB gene } \\
\text { 3) Impermeability } \\
\text { 4) Efflux }\end{array}$ \\
\hline Glycopeptides & $\begin{array}{l}\text { Cell wall } \\
\text { synthesis }\end{array}$ & $\begin{array}{l}\text { Inhibiting cross-linkage of } \\
\text { peptidoglycan layers. }\end{array}$ & $\begin{array}{l}\text { 1) Acquisition of van genes, } \\
\text { resulting in production of low- } \\
\text { affinity peptidoglycan } \\
\text { precursors with altered } \\
\text { termini. } \\
\text { 2) Thicker cell wall } \\
\text { (peptidoglycan) } \\
\text { GISA/hGISA }\end{array}$ \\
\hline Oxazolidinones & $\begin{array}{l}\text { Protein } \\
\text { synthesis }\end{array}$ & $\begin{array}{l}\text { Inhibiting formation of the } \\
70 \mathrm{~S} \text { initiation complex by } \\
\text { binding to the } 50 \mathrm{~S} \\
\text { ribosomal subunit. }\end{array}$ & $\begin{array}{l}\text { Mutations in the } 23 \mathrm{~S} \text { rRNA } \\
\text { gene, resulting in alterations in } \\
\text { the antibiotic binding site of } \\
\text { ribosomes. }\end{array}$ \\
\hline Quinolones & $\begin{array}{l}\text { Nuclein acid } \\
\text { synthesis }\end{array}$ & $\begin{array}{l}\text { Inhibiting DNA gyrase } \\
\text { and topoisomerase IV, } \\
\text { responsible for the folding } \\
\text { and supercoiling of DNA. }\end{array}$ & $\begin{array}{l}\text { 1) Mutations in the } \operatorname{gyr}(A) \\
\text { and/or parC genes, encoding } \\
\text { DNA gyrase and } \\
\text { topoisomerase IV, resulting in } \\
\text { alterations in the antibiotic } \\
\text { target. } \\
\text { 2) Efflux }\end{array}$ \\
\hline Rifamycins & $\begin{array}{l}\text { Nuclein acid } \\
\text { synthesis }\end{array}$ & $\begin{array}{l}\text { Inhibiting DNA-dependent } \\
\text { RNA polymerase. }\end{array}$ & $\begin{array}{l}\text { Mutations in the } r p o B \text { gene, } \\
\text { encoding the } \beta \text {-subunit of the } \\
\text { RNA polymerase, resulting in } \\
\text { alteration of amino acids in the } \\
\text { RNA polymerase. }\end{array}$ \\
\hline
\end{tabular}




\subsection{MRSA}

The first MRSA strain was isolated in 1961 in the UK, shortly after the introduction of methicillin into clinical practise [36]. MRSA strains carry the mecA gene, encoding an additional methicillin-resistant PBP (PBP2a). The PBP2A has very low affinity for $\beta$-lactam antibiotics, and takes over the function of the native PBPs in the presence of $\beta$-lactam antibiotics. It also needs a native transglycosidase to function [37].

MRSA is one of the leading pathogens causing HA (nosocomial) infections. A high frequency of HA-MRSA strains are multi-resistant, showing resistance to all $\beta$-lactam antibiotics, and also have intrinsic or acquired resistance to other types of antibiotics [38]. There are a few successful HA-MRSA clones, which have been transmitted worldwide (pandemic clones). These clones are suggested to be transmitted at a higher frequency between patients, and to cause a significantly higher incidence of infection beyond that of the background incidence [39-40]. The pandemic clones are described by their clonal complex (CC) or sequence type (ST) determined by multi-locus sequence typing (MLST), pulsed-field gel electrophoresis (PFGE) pattern, staphylococcal protein A (spa) type or by their lineage type. Each clone also carries a particular staphylococcal cassette chromosome element, carrying the mecA gene (SCCmec). The pandemic clones include $\mathrm{CC} 5, \mathrm{CC} 8, \mathrm{CC} 22, \mathrm{CC} 30$, CC45 and ST239 [40-41]. The distribution of pandemic clones varies with geography. The predominant clones in the USA are CC5-SCCmec II (USA100), CC5-SCCmec IV (USA800) and CC8-SCCmec IV (USA500), whereas in the UK they are CC22-SCCmec IV (EMRSA15) and CC30-SCCmec II (EMRSA-16). In Germany, CC5 of mixed SCCmec carriage (and including ST228 and ST111) and CC45-SCCmec IV dominate. ST239-SCCmec III is the predominant clone in South America and Asia. Sweden and the other Scandinavian countries have a low prevalence of HA-MRSA [40], probably due to effective epidemiological surveillance programs and infection control procedures.

\subsubsection{Community-associated MRSA}

Although described as a typical nosocomial pathogen, MRSA has now emerged in the community as well. Community-associated (CA) MRSA are infections affecting healthy individuals who have had no recent contact with health care, and lack the typical risk factors known for HA-MRSA [42]. CA-MRSA is primarily associated with SSTIs, although more 
severe infections such as bacteraemia, necrotising pneumonia and septic shock occur.

Compared to HA-MRSA, strains of CA-MRSA carry different SCCmec types, mainly show resistance to $\beta$-lactam antibiotics, and have lower MIC values. However, they tend to be more virulent than HA-MRSA [15]. The toxin PVL is commonly found among CA-MRSA, which may explain their high virulence [12-15]. In recent years, CA-MRSA has become increasingly prevalent in hospitals and other health care facilities, and may eventually replace traditional MRSA strains. Likewise, HA-MRSA may circulate in the community. Thus, it is becoming increasingly difficult to differentiate the two by epidemiological definitions and risk factors $[39,43-44]$.

\subsubsection{Livestock-associated MRSA}

MRSA is not limited to humans. Livestock-associated (LA) MRSA is mainly associated with CC398 and can be found in intensively reared production animals such as pigs, poultry or cattle. However, LA-MRSA CC398 has no pronounced host specificity and can also colonize or infect companion animals such as cats, dogs, horses and even humans [45-46]. LA-MRSA CC398 can be transmitted from pigs to humans, and persons in close contact with pigs are at significant risk for colonisation [47-49]. Human carriage of LA-MRSA CC398 is typically asymptomatic, although sporadic cases of serious disease have been reported [50-52]. LAMRSA CC398 probably originated from methicillin-susceptible S. aureus (MSSA) in humans, then was transmitted to pigs wherein SCCmec was acquired, and is now seen reinfecting humans [53].

\subsection{3 mecC}

Recently, a highly divergent $m e c A$ gene $(m e c C$ ) was detected in isolates from both humans and dairy cattle. This mecC gene has been identified and localised to SCCmec type XI [5456]. MRSA strains shown to carry mecC typically belong to lineages reported in cattle (CC49, CC130, CC425, CC599 and CC1943), which suggests an animal origin [57-58]. A major concern is the difficulty of detecting mecC-positive MRSA with conventional confirmatory tests for MRSA, which may be a result of excessively low resistance levels of oxacillin and cefoxitin (especially oxacillin) [58-59]. Commercially available MRSA assays have also been 
shown to be unreliable. However, assays are currently being developed for the accurate detection of $m e c C$ [58].

\subsection{Mobile genetic elements}

S. aureus is capable of rapid adaption to conditions of high selective pressure from the environment. Transfer of deoxyribonucleic acid (DNA) by mobile genetic elements (MGEs) between bacterial cells (horizontal transfer) is one way to promote fitness and survival. MGEs are fragments of DNA that encode a variety of virulence- and antibiotic resistance factors, and may consist of chromosome cassettes, insertion sequences, pathogenicity islands, phages, plasmids and transposons. Horizontal transfer of MGEs occurs via transformation (uptake of free DNA from the environment), transduction (DNA transfer via a bacteriophage) or conjugation (direct contact between bacterial cells) [60-61]. As a consequence of the limited ability of $S$. aureus to acquire DNA from the environment (low natural competence), most horizontal transfer occurs via transduction or transformation [62].

\subsection{SCCmec}

SCCmec elements are complex MGEs, which can encode antibiotic resistance and/or virulence factors $[58,61]$. The emergence of MRSA is due to the acquisition of SCCmec into the chromosome of MSSA [63-67]. Studies have shown that SCC and mecA originally existed as individual genetic components, and it is suggested that SCCmec may have been acquired from multi-resistant coagulase-negative staphylococci such as S. sciuri [68-70].

SCCmec integrates at the integration site sequence (ISS) for SCC at the $3^{\prime}$ end of an open reading frame (ORF) designated $\operatorname{orf} X$, which encodes a ribosomal methyltransferase [71]. SCCmec is characterised by a ccr-and a mec gene complex. The ccr gene complex is composed of one or two recombinase genes and surrounding ORFs, several of which have unknown functions. The recombinase gene(s) are responsible for site- and orientation-specific integration and excision of SCCmec [67]. There are currently eight types of the $c c r$ gene complex in staphylococci. The type 1,2, 3, 4, 6, 7 and $8 \mathrm{ccr}$ gene complexes are composed of $c c r A$ and $c c r B$ in combination ( $c c r A B)$, and type $5 c c r$ of $c c r C$ alone (Table 2) [72]. The mec gene complex is composed of mecA, intact or truncated sets of its regulatory genes mecRI (encoding the signal transducer protein MecR1) and mecl (encoding the repressor protein 
MecI), and associated insertion sequences IS431 and IS1272 [67]. When MecI binds to the promoter region of $m e c A$, the transcription of $m e c A$ is repressed. If a $\beta$-lactam antibiotic binds to MecR1, the polypeptide with protease activity releases from the MecR1 to degrade MecI, resulting in an increase of the transcription of mecA [73]. Six classes of the mec gene complex have currently been identified in staphylococci: class A, B, C1, C2, D and E (Table 3) [72]. The remaining parts of SCCmec are called joining (J) regions and consist of three parts: J1, J2 and J3. The JI region is located between the genome right junction and the ccr gene complex, whereas the region from the $c c r$ gene complex to the mec gene complex is called the $\mathrm{J} 2$ region. The $\mathrm{J} 3$ region spans from the mec gene complex to orf $X$ [67]. The J-regions contain other genes, mainly ORFs with unknown or non-essential functions, but also other antibiotic resistance genes, besides $m e c A$, that have been acquired by plasmids or transposons [61].

SCCs are classified into SCCmec or non-SCCmec groups. Non-SCCmec elements may contain other antibiotic resistance genes than $m e c A$ or virulence-associated genes [58, 61]. SCC elements carry a $c c r$ gene complex but lack a mec gene complex, whereas pseudoSCCmec elements carry a mec gene complex but lack a $c c r$ gene complex. Pseudo-SCC elements lack both the $c c r$ - and mec gene complex. They can be differentiated into three groups: (i) arginine catabolic mobile elements (ACMEs); (ii) SCC-like elements, chromosome cassettes or SCCmec insertion site genomic sequences; and (iii) SCCmec remnants, which lack the $c c r$ genes and $m e c A$ but have a genomic organisation almost identical to a previously described SCCmec element, apart from the absence of a contiguous region of $c c r$ and mec and intervening genes. SCCmec remnants can either be derived from SCCmec elements with the excision of mecA and other sections of SCCmec, or can represent SCCmec precursors prior to the acquisition of $m e c A$ [58]. Carrying a SCCmec element is thought to be a fitness burden for S. aureus [74]. The ability of SCCmec elements to be inserted or excised from the chromosome demonstrates how $S$. aureus is able to adapt to its environment. The excision of SCCmec can be complete or partial. In the latter case, some elements are left behind at the ISS. Partial excision of SCCmec from the chromosome of a HA-MRSA strain may result in MSSA with a retained resistance to antibiotics other than $\beta$-lactam antibiotics [75]. This phenomenon has previously been described in studies where a high proportion of the investigated MSSA isolates were considered to derive from MRSA with partial excision of SCCmec [76-77]. 
Table 2: Currently identified $c c r$

gene complexes in staphylococci.

\begin{tabular}{ll}
\hline$c c r$ gene complex & $c c r$ genes \\
\hline type 1 & A1B1 \\
type 2 & A2B2 \\
type 3 & A3B3 \\
type 4 & A4B4 \\
type 5 & C1 \\
type 6 & A5B3 \\
type 7 & A1B6 \\
type 8 & A1B3 \\
\hline
\end{tabular}

Table 3: Currently identified mec gene complexes in staphylococci.

\begin{tabular}{|c|c|}
\hline mec gen & \\
\hline class $\mathrm{A}$ & IS431-mесA-mecR1-mecI \\
\hline class B & IS431-mecA- $\Delta$ mecRI-IS1272 \\
\hline class $\mathrm{C} 1$ & $\begin{array}{l}\text { IS431-mecA- } \Delta m e c R l-\text { IS } 431 \\
\text { (two IS431 are arranged in the same direction) }\end{array}$ \\
\hline class $\mathrm{C} 2$ & $\begin{array}{l}\text { IS } 431-m e c A-\Delta m e c R 1-\text { IS } 431 \\
\text { (two IS431 are arranged in the opposite direction) }\end{array}$ \\
\hline class D & IS431-mecA- $\Delta m e c R 1$ \\
\hline class E & blaZ-mec $A_{\mathrm{LGA} 251}-m e c R 1_{\mathrm{LGA} 251}-m e c I_{\mathrm{LGA} 251}$ \\
\hline
\end{tabular}

\subsubsection{SCCmec types}

SCCmec elements are classified according to the combination of the $c c r$ - and mec gene complex [67]. Currently, there are eleven different types of SCCmec, which are defined by $c c r$ type (indicated by a number) and mec class (indicated by an uppercase letter). The SCCmec types are: type I (1B), type II (2A), type III (3A), type IV (2B), type V (5C2), type VI (4B), type VII (5C1), type VIII (4A), type IX (1C2), type X (7C1) and type XI (8E) [72]. Subtypes of each SCCmec type are defined by the structural differences in the J-regions. Structural differences in the J-regions are the primary explanation for the size differences of the SCCmec types [67].

Strains with SCCmec type I, II and III are most frequently found in isolates from nosocomial infections, whereas CA-strains predominantly carry SCCmec type IV or V. SCCmec type IV is also characteristic of some nosocomial strains [4, 78-82]. SCCmec type IV is the most common type found in MRSA worldwide. This type is also the most variable 
with eight subtypes, which is probably a result of its higher mobility compared to the other SCCmec types [83-84]. The most recently described SCCmec elements, type IX, X and XI have all been found in MRSA strains considered to be of animal origin, and carry at least one operon encoding resistance to heavy metals, which appears to be an attribute of SCCmec elements originating in animals [58].

\subsection{Nosocomial infections}

Nosocomial infections are infections acquired during health care, which were not present or incubating at admission. Infections occurring more than 48 hours after admission are usually considered nosocomial [85-86]. They represent a problem associated with excess morbidity and mortality, extended hospitalisations and increased costs [85, 87].

Nosocomial infections can be either endogenous or exogenous. Endogenous infections are caused by antibiotic-resistant pathogens originating from the patient's own micro flora, whereas exogenous infections are cases of cross-transmission of pathogens via direct contact between patients, health care workers' hands or clothes, or indirectly by contaminated equipment etc. [86]. Most nosocomial infections are endemic, i.e. sporadic infections, which constitute the background incidence within a health care facility. However, some cases appear as clonal outbreaks, where a bacterial strain from a common source is transmitted to a large number of patients in a defined time period and geographic area [88-89]. Although transmission of nosocomial infections has mainly been studied at the level of single hospitals, nosocomial pathogens may be transmitted between different hospitals by referred patients. Thus, hospitals become connected through their shared patients, and the degree to which patients are shared between hospitals crucially influences the rate of nosocomial infection [90-94]. The most common types of nosocomial infections include bloodstream infections, pneumonia, surgical site infections and urinary tract infections [85-86]. Hospitalised patients are more often vulnerable to bacterial infections due to impaired immune defences, frequent use of invasive devices and procedures, and repeated and long-term courses of antibiotics. The elderly and young children are usually more susceptible [85, 95-96].

The most important method of preventing nosocomial infections is maintenance of basic hygiene guidelines among health care workers, such as hand washing before and after patient contact, and the appropriate use of alcohol-based disinfectants. Barrier equipment, such as 
disposable gloves and plastic aprons or gowns, should be used when necessary, and should be removed directly after each risky contact and changed between procedures. Short-sleeved clothing should be worn and should be changed at least every day. Hands and forearms should be free from jewellery. Sharps and clinical waste should be appropriately handled and disposed of. Medical equipment should be completely sterilised before use, and health care facilities should offer a sanitary environment. In addition, the use of antibiotics must be controlled, since extended use might result in development of antibiotic-resistant bacterial strains. It is of the utmost importance to educate health care workers about the epidemiology, pathogenesis and general routes of transmission of nosocomial pathogens. Education is required both to disseminate basic information and to encourage compliance with infection control measures [97-98].

\subsubsection{Investigation of nosocomial outbreaks}

Outbreaks of nosocomial infections should be identified and investigated immediately on suspicion to prevent further transmission. An outbreak investigation involves identification of the causative pathogen, its mode of transmission, the occurrence and source, and to formulate recommendations to stop the transmission. Isolates cultured from patients suspected of being part of a clonal outbreak should be saved for future strain typing at the clinical microbiology laboratory [88-89, 99-100].

Identifying different types of an organism within a species is called typing. Traditional typing methods based on phenotype, such as serotype, biotype, phage-type and antibiogram have nowadays been supplemented or replaced with molecular genotyping methods, which have the ability to type a broader array of bacterial species and supply reliable, definitive epidemiological data [101]. Genotyping methods can be characterised in terms of typeability (the ability to assign an unambiguous result to each isolate), reproducibility (the ability to yield the same result upon repeat testing of a bacterial isolate), discriminatory power (the ability to differentiate among epidemiologically unrelated isolates, ideally assigning each to a different type), ease of performance and interpretation [102]. The goal of typing is to provide laboratory evidence that epidemiologically related isolates (related by time and place) collected during an outbreak are also genetically related (clonal), and thus represent the same strain. Typing and epidemiologic investigations should always be developed independently but analysed together to determine if an outbreak has occurred [88, 101]. 


\subsubsection{PFGE}

PFGE was developed in 1984 by Schwartz and Cantor [103], and is based on restriction enzyme analysis of the bacterial DNA. The restriction enzyme used for staphylococci is SmaI, which cuts the DNA molecule at the CCC-GGG sequence. The DNA is digested into approximately 10-30 fragments with a range of approximately $10-1000 \mathrm{~kb}$ each. To prevent breakage of the large DNA molecules, intact cells are embedded in agarose, lysed and deproteinised in situ. One of the most commonly used models in PFGE is the contourclamped homogeneous electric field (CHEF), where the negatively charged DNA is run through a flat gel matrix of agarose towards the positive pole. In contrast to conventional electrophoresis, where the electric current is applied to the gel in a single direction, the current is provided in pulses that alternate from three sets of electrodes, resulting in a higher level of fragment resolution $[100,102]$. The resulting DNA patterns can be compared to determine their relatedness.

According to the criteria proposed by Tenover et al. [101], isolates are designated as clonal if their PFGE patterns have the same number of bands, and the corresponding bands are of the same size. These isolates are considered to represent the outbreak pattern. Isolates differing by two to three bands (consistent with one genetic event) are considered closely related, whereas difference by four to six bands (two genetic events) results in a possible relatedness. Isolates are considered unrelated when their PFGE patterns differ by seven or more bands (three or more genetic events).

\subsubsection{MLST}

MLST is a method based on the DNA sequences of internal fragments of multiple (usually seven: $\operatorname{arcC}$, aroE, glpF, gmk, pta, tpi and yqiL) housekeeping genes. Approximately 450-500 bp internal fragments of each gene are amplified by polymerase chain reaction (PCR), and subsequently DNA sequenced on both strands by using an automated DNA sequencer. A distinct allele is assigned to each of the different sequences of each housekeeping gene. The alleles define the $S$. aureus lineage, resulting in an allelic profile designated ST [73, 104]. Strains are grouped into a CC when five of the seven housekeeping genes have identical sequences. The ancestor of the $\mathrm{CC}$ is the ST which has the largest number of single-locus variants [105]. 


\subsection{4 spa typing}

The sequencing of the polymorphic region $\mathrm{X}$ of the protein A gene, containing a variable number of 24-bp-repeat regions flanked by well-conserved regions, is called spa typing and was developed by Frenay et al. [106]. The staphylococcal protein A is a stable cell wall protein only present in S. aureus, and is composed of three regions: (i) the C-terminal sequence; (ii) the region $\mathrm{X}$; and (iii) the $\mathrm{N}$-terminal sequence. The region $\mathrm{X}$ is the only polymorphic region and its function is unknown. The typing is based on: (i) the exact DNA sequence of the single repetitions; (ii) the number of repeats; and (iii) the order of the different repeats $[73,104,107]$.

\subsubsection{Microarray-based genotyping}

A DNA microarray is a collection of microscopic DNA spots attached in an ordered fashion to a solid surface. Each DNA spot contains picomoles $\left(10^{-12}\right.$ moles) of a specific DNA sequence, known as probes. The probes are used to detect complementary nucleotide sequences in particular bacterial isolates. Thus, genes which serve as markers for specific bacterial strains or allelic variants of a gene, that is present in all strains of a particular species, can be detected. The probes may be PCR products (>200 bp) or primers (>70 bp). The method is based on extraction of DNA from the bacterium of interest, subsequent labelling (chemically or by an enzymatic reaction), and hybridisation to a DNA microarray. Unbound DNA is removed during the following washing steps, and the signal from a successful hybridisation between the labelled DNA and an immobilised probe can be measured automatically. Finally, the data produced are analysed using dedicated software. The method facilitates a genotype-based assessment of the virulence and of the antibiotic resistance of a given isolate. The overall hybridisation profile can also be used as a fingerprint, or a dataset, which may allow elucidation of the relatedness between different isolates, and their allocation to strains [104, 108].

\subsubsection{Comparison of molecular genotyping methods}

PFGE is currently considered the gold standard for typing of staphylococci. Because of its high discriminatory power it is especially suitable for local outbreak investigation. However, because strain characterisation by PFGE is based on pattern matching, inter-laboratory 
comparison is problematic. Furthermore, it is a technically demanding and time-consuming method, and its interpretation leaves room for subjectivity. DNA sequence-based methods are becoming more frequently used because of the ease with which sequence data can be transferred between laboratories via the Internet. MLST is a highly discriminatory typing method, and the low mutation rate of the seven housekeeping genes makes MLST more suitable for long-term global epidemiological studies. However, it is an expensive and laborious method, which lacks the resolving power of PFGE. spa typing has been shown to have equal stability to MLST, and possesses a significant number of practical advantages over PFGE in terms of speed, interpretation and inter-laboratory comparison [73, 104, 109-110]. These sequence-based typing methods are less useful for epidemiological investigation of local outbreaks because they lack the discriminatory power of PFGE for differentiating among closely related isolates. Thus, PFGE and sequence-based typing are complementary when investigating isolate relationships, with PFGE providing fine-scale differentiation and sequence-based typing being better at revealing the overall picture [109].

Compared to PFGE and sequence-based typing methods, microarray-based genotyping yields more information than just the genetic relatedness among bacterial strains of a species. Bacteria can be simultaneously genotyped and profiled to determine their antibiotic resistance and virulence potential. In addition, the whole genome microarray approach is a useful alternative to whole genome sequencing, which saves time, effort and expense [104].

\subsection{PCR}

PCR was developed by Mullis et al. [111] in 1986, and is a method for amplification of specific DNA fragments. The PCR requires two specific oligonucleotides (primers) complementary to the DNA strand, a heat-stable DNA polymerase to initiate the DNA synthesis, and deoxyribonucleotide triphosphates (dNTPs), which are building blocks of the synthesised DNA strands. The PCR is carried out in three steps: (i) denaturation of the double-stranded DNA to make the DNA accessible for the DNA polymerase; (ii) annealing of the primers to the single-stranded DNA; and (iii) incorporation of the nucleotides by the polymerase and subsequent extension of the complementary DNA strand. The PCR cycle is repeated 25-40 times, and the different steps take place at specific temperatures and times. The DNA polymerase generally has an optimum temperature of $72{ }^{\circ} \mathrm{C}$ [112]. 
Conventional PCR requires separation of the PCR products by electrophoresis to confirm that the expected DNA has been amplified. In contrast, real-time PCR allows both amplification of the DNA and detection of the PCR product in a closed system. The amplified DNA is fluorescently labelled, and a fluorescent signal is measured in each cycle. The signal is directly proportional to the amplified DNA, which makes it possible to follow the PCR in "real time". Thus, the original amount of DNA can be determined based on the amount of PCR product during the exponential phase [113].

\subsection{DNA sequencing}

DNA sequencing is the process of determining the precise order of the nucleotides adenine (A), thymine (T), guanine $(\mathrm{G})$ and cytosine $(\mathrm{C})$ within a DNA molecule. The most frequently used DNA sequencing method is the Sanger method [114], which is based on the inhibition of DNA polymerase by modified nucleotides (dideoxynucleotides). The DNA to be sequenced is added to a mixture of normal nucleotides, dideoxynucleotides, DNA polymerase and a DNA primer, after which a PCR programme is initiated. Dideoxynucleotides lack a 3'-OH group required for the formation of a phosphodiester-bond between two nucleotides, causing DNA polymerase to terminate the DNA extension whenever a dideoxynucleotide is incorporated. In addition, dideoxynucleotides are radioactively or fluorescently labelled for detection in automated sequencing machines. Nowadays, Sanger sequencing has been replaced by nextgeneration sequencing methods, especially for large-scale automated analyses.

Pyrosequencing is based on sequencing during DNA synthesis. Each incorporation of a nucleotide by DNA polymerase results in the release of pyrophosphate. The light emitted upon pyrophosphate release is directly proportional to the number of nucleotides incorporated into the growing DNA chain. Only one of the four possible nucleotides is able to be incorporated at a time. Unincorporated nucleotides are degraded before the next nucleotide is added for synthesis. The process is repeated with each of the four nucleotides, which eventually makes it possible to determine the DNA sequence [115]. In massive parallel 454 pyrosequencing the DNA is associated with agarose beads, carrying primers complementary to the 454-specific adapter sequences on the DNA. These beads are then isolated into individual oil:water micelles containing PCR reactants (emulsion PCR). The amplified DNA is thereafter pyrosequenced [116]. 


\section{Aims}

The aims of this thesis were to:

- Investigate the genetic relatedness between multi-resistant MSSA found in southeast Sweden.

- Perform epidemiological investigation(s) including patients carrying genetically related isolates in order to delineate nosocomial transmission.

- Investigate if the multi-resistant MSSA found were derived from MRSA by carrying remnants of SCCmec, and if so to characterise the SCCmec element(s).

- Examine the isolates with respect to genes encoding virulence factors, such as the PVL genes. 


\section{Materials and methods}

\subsection{Settings}

In Papers I and II, clinical bacterial isolates from patients in Östergötland County (with an estimated 434000 inhabitants) were included. The Östergötland County Council includes three hospitals: one tertiary care hospital (Linköping University Hospital) and two secondary care hospitals (Vrinnevi Hospital and Motala Hospital).

In Paper III, clinical bacterial isolates from patients in southeast Sweden were included. Southeast Sweden is a region constituted by the three County Councils of Jönköping, Kalmar and Östergötland, between whose hospitals a high exchange of patients occurs. The region has an estimated 1006000 inhabitants and includes one tertiary care hospital (Linköping University Hospital in Östergötland County) and eight secondary care hospitals (Ryhov Hospital, Höglands Hospital and Värnamo Hospital in Jönköping County; Kalmar County Hospital, Västervik Hospital and Oskarshamn Hospital in Kalmar County; and Vrinnevi Hospital and Motala Hospital in Östergötland County).

Several primary care centres are also located in each county and contributed to the collection of bacterial isolates in Paper I-III.

\subsection{Bacterial isolates}

In Paper I, a search was performed in the database of the clinical microbiology laboratory at Linköping University Hospital for MSSA with concomitant resistance to erythromycin, clindamycin and tobramycin (ECT-R), isolated between January 2004 and October 2007 (one isolate per patient and year). To investigate whether genetically related isolates were frequent among susceptible $S$. aureus in Östergötland County, a control group of five ECT-S MSSA isolates per year of study was also included. These isolates were randomly selected from a culture collection of $S$. aureus from inpatients admitted to any one of the hospitals in the county. The ECT-R MSSA isolates were compared with two MRSA isolates (spa type t032 and t149) isolated during the MRSA outbreak in 2005, which were representatives of the particular outbreak clones. Also included were three MRSA isolates of spa type t002 from Östergötland County (from three different patients in 2005, 2006 and 2007, respectively), and one MRSA isolate of spa type t088 (part of ST-5) from the Swedish Institute for Infectious 
Disease Control (SMI) (spa type and ST data provided by SMI). The latter isolate was chosen as a representative of isolates found in 1997 in Stockholm, Sweden. Since 2000, when MRSA became a notifiable disease in Sweden, isolates that are part of ST-5, or related STs that are also part of MLST CC5, have frequently been found in Sweden. The same ECT-R MSSA study population was later included in Paper II.

In Paper III, consecutive clinical isolates of MSSA were prospectively collected between June 2009 and June 2010 at the clinical microbiology laboratories at Ryhov Hospital, Kalmar County Hospital and Linköping University Hospital, respectively. Three different groups of isolates, defined by antibiotic resistance profile: clindamycin (group 1), tobramycin (group 2) or both clindamycin and tobramycin (group 3), were included with a maximum of 20 isolates per group and location (one isolate per patient). Isolate ECT-R2, representing the ECT-R outbreak clone, previously whole genome sequenced in Paper II, was included as a reference in the microarray analysis.

Well-characterised positive and negative control strains were included and are described in each performed analysis.

\subsection{Antibiotic susceptibility testing (Paper I and III)}

Antibiotic susceptibility testing was performed using the disk diffusion method (Oxoid AB, Sweden) and Etest (bioMérieux, France) according to EUCAST. All isolates were tested for erythromycin, clindamycin, tobramycin, gentamicin, fusidic acid, rifampicin and moxifloxacin. In addition, the isolates included in Paper III were tested for vancomycin and cefoxitin. Isolates were classified as S, I or R according to the EUCAST species-related breakpoints.

\subsection{Detection of the nuc- and $m e c A$ gene (Paper II and III)}

Detection of the $n u c$ - and mecA gene was performed by real-time PCR using nuc-specific primers (nuc-1: 5'-GCGATTGATGGTGATACGGTT-3', nuc-2: 5'-

AGCCAAGCCTTGACGAACTAAAGC-3’) and mecA-specific primers (mecA-1: 5'GCAATCGCTAAAGAACTAAG-3', mecA-2: 5'-GGGACCAACATAACCTAATA-3') (Invitrogen $\mathrm{AB}$, Sweden). Before PCR analysis, isolates were cultured overnight at $37{ }^{\circ} \mathrm{C}$ on 
blood agar plates. Four colonies were mixed with StaphLys (1 M Tris-HCl pH 7.6, Tween 20, Igepal CA-630 (Sigma-Aldrich, Germany)) and Proteinase K 20 mg/mL (Roche Diagnostics, IN, USA). For $n u c$, the PCR reaction mixture consisted of $2 \mu \mathrm{L}$ of the DNA preparation together with $0.25 \mu \mathrm{M}$ of each primer, $10 \mu \mathrm{L}$ QuantiTect SYBR Green PCR master mix and $5.5 \mu \mathrm{L}$ RNase-free water (Qiagen $\mathrm{AB}$, Sweden), with addition of $12.5 \mathrm{nmol} \mathrm{MgCl}_{2}$ in a final volume of $20 \mu \mathrm{L}$. For $m e c A, 1 \mu \mathrm{M}$ of each primer was used. The PCR was performed using a Rotor-Gene 3000 thermal cycler (Corbett Robotics, Australia) with the following protocol: an initial denaturation at $95^{\circ} \mathrm{C}$ for $15 \mathrm{~min}$, followed by 40 cycles of three steps consisting of denaturation at $95{ }^{\circ} \mathrm{C}$ for $20 \mathrm{sec}$, annealing at $55^{\circ} \mathrm{C}$ for $20 \mathrm{sec}$, and extension at $72{ }^{\circ} \mathrm{C}$ for 30 sec. Each run was completed by a melting point analysis at $60-95{ }^{\circ} \mathrm{C}$ with a $0.8{ }^{\circ} \mathrm{C}$ transition rate. For each run a MRSA strain (CCUG 35601), a S. aureus strain (ATCC 29213) and a $S$. saprophyticus strain (CCUG 3706) were processed along with the unknown isolates and used as positive and negative controls.

\subsection{Detection of antibiotic resistance genes (Paper II and III)}

In Paper II, detection of the genes coding for resistance to erythromycin and clindamycin (ermA located on transposon Tn554), and tobramycin (ant(4') located on plasmid pUB110) was performed by conventional PCR with an Eppendorf Thermal Cycler (Eppendorf AG, Germany), followed by size analysis of DNA fragments with QIAxcel Biocalculator (Qiagen $\mathrm{AB}$, Sweden), which is a multicapillary electrophoresis system for automatic size analysis of DNA fragments. ermA-specific primers (ermA-1: 5'-CTTCAAAGCCTGTCGGAATTG3'and ermA-2: 5'-ATCGGATCAGGAAAAGGACA-3') and ant (4')-specific primers (ant(4')-1: 5'-TGAATATGCAGGCAAATGGC-3' and ant(4')-2: 5'-

TATCCGTGTCGTTCTGTCC-3’) were designed using OligoAnalyzer 3.1 software (Integrated DNA Technologies, Belgium). DNA was prepared as described for detection of the $n u c$ - and mecA gene. The PCR reaction mixture consisted of $1 \mu \mathrm{L}$ of the DNA preparation together with $0.4 \mu \mathrm{M}$ of each primer, $12.5 \mu \mathrm{L}$ HotStar PCR mastermix and 9.5 $\mu \mathrm{L}$ RNase-free water (Qiagen $\mathrm{AB}$, Sweden) in a final volume of $25 \mu \mathrm{L}$. The thermal cycling protocol was as follows: $15 \mathrm{~min}$ at $95{ }^{\circ} \mathrm{C}$ for initial denaturation, followed by 35 cycles of three steps consisting of $30 \mathrm{sec}$ at $95{ }^{\circ} \mathrm{C}$ for denaturation, $30 \mathrm{sec}$ at $40.5^{\circ} \mathrm{C}$ for annealing, and $1 \mathrm{~min}$ at 72 ${ }^{\circ} \mathrm{C}$ for extension. A final extension step was performed for $10 \mathrm{~min}$ at $72{ }^{\circ} \mathrm{C}$. A well- 
characterised SCCmec type II MRSA strain (N315) and a S. aureus strain (ATCC 29213) were included as a positive and a negative control, respectively.

In Paper III, detection of antibiotic resistance genes is described in microarray-based genotyping.

\subsection{Detection of virulence genes (Paper I and III)}

In Paper I, detection of the PVL genes was performed by real-time PCR using the PVLspecific primers lukS-PV and lukF-PV (Invitrogen AB, Sweden) as described by Johnsson et al. [117]. Before PCR analysis, isolates were cultured overnight at $37^{\circ} \mathrm{C}$ on blood agar plates. Approximately $1 \mu \mathrm{L}$ colonies was mixed with $200 \mu \mathrm{L}$ RNase-free water (Qiagen AB, Sweden). The mixture was heated at $99^{\circ} \mathrm{C}$ for $10 \mathrm{~min}$, and the DNA was extracted using a GenoVision GenoM-4 extraction-robot (GenoVision AS, USA). The PCR reaction mixture consisted of $2 \mu \mathrm{L}$ of the DNA preparation together with $0.45 \mu \mathrm{M}$ of each primer, $11 \mu \mathrm{L}$ QuantiTect SYBR Green PCR master mix and 6.5 $\mu \mathrm{L}$ RNase-free water (Qiagen AB, Sweden), with addition of $12.5 \mathrm{nmol} \mathrm{MgCl}_{2}$ in a final volume of $22 \mu \mathrm{L}$. The PCR was performed using a Rotor-Gene 3000 thermal cycler (Corbett Robotics, Australia) with the following protocol: $15 \mathrm{~min}$ at $95{ }^{\circ} \mathrm{C}$ for initial denaturation, followed by 40 cycles of three steps consisting of $20 \mathrm{sec}$ at $95{ }^{\circ} \mathrm{C}$ for denaturation, $20 \mathrm{sec}$ at $55^{\circ} \mathrm{C}$ for annealing, and $30 \mathrm{sec}$ at $72{ }^{\circ} \mathrm{C}$ for extension. Each run was completed by a melting point analysis at $60-95{ }^{\circ} \mathrm{C}$ with a $1{ }^{\circ} \mathrm{C}$ transition rate. For each run a PVL-positive MSSA strain (CCUG 47167) and a PVLnegative $S$. saprophyticus strain (CCUG 3706) were processed along with the unknown isolates and used as a positive and a negative control, respectively.

In Paper III, detection of virulence genes is described in microarray-based genotyping.

\subsection{PFGE (Paper I)}

Genomic DNA extraction, restriction enzyme digestion with SmaI, and PFGE using the CHEF-model were performed according to the GenePath Group 1 Reagent Instruction Manual Kit (Bio-Rad Laboratories AB, Sweden). The gel was stained in an ethidium bromide solution after each run, and the PFGE patterns were interpreted visually in accordance with the criteria proposed by Tenover et al [101]. A well-characterised control strain (NCTC 8325) and a 
DNA size standard (Lambda Ladder) (Bio-Rad Laboratories AB, Sweden) were processed along with the unknown isolates in each run.

\section{8 spa typing (Paper I and III)}

spa typing was performed by real-time PCR according to the Ridom StaphType protocol (Ridom GmbH, Germany). spa-specific primers, containing an M13 sequence primer (Invitrogen $\mathrm{AB}$, Sweden), were used to amplify the spa gene in real-time PCR. DNA was prepared as described for detection of PVL. The PCR reaction mixture consisted of $2 \mu \mathrm{L}$ of the DNA preparation together with $0.5 \mu \mathrm{M}$ of each primer, $10 \mu \mathrm{L}$ QuantiTect SYBR Green PCR master mix and 5.5 $\mu \mathrm{L}$ RNase-free water (Qiagen AB, Sweden), with addition of 12.5 $\mathrm{nmol} \mathrm{MgCl}_{2}$ in a final volume of $20 \mu \mathrm{L}$. The PCR was performed using a Rotor-Gene 3000 thermal cycler (Corbett Robotics, Australia) with the following protocol: an initial denaturation at $95{ }^{\circ} \mathrm{C}$ for $15 \mathrm{~min}$, followed by 35 cycles of three steps consisting of denaturation at $94{ }^{\circ} \mathrm{C}$ for $25 \mathrm{sec}$, annealing at $60{ }^{\circ} \mathrm{C}$ for $25 \mathrm{sec}$, and extension at $72{ }^{\circ} \mathrm{C}$ for 40 sec. Each run was completed by a melting point analysis at $60-95{ }^{\circ} \mathrm{C}$ with a $1{ }^{\circ} \mathrm{C}$ transition rate. Samples were sent to MWG Biotech (MWG Biotech, Germany) for sequencing. spa types were determined using Ridom StaphType software version 1.4 (Ridom GmbH, Germany), and analysed by the BURP algorithm with the following default parameters: spa types shorter than five repeats were considered non-groupable, and were therefore excluded from the analysis. spa types belonged to the same $\mathrm{CC}$ if the cost (reflecting the evolutionary distance between two isolates) was less than, or equal to six.

In Paper III, alternative spa primers 1084F: 5'-ACAACGTAACGGCTTCATCC-3' and 1618R: 5'-TTAGCATCTGCATGGTTTGC-3' (Genbank accession no. J01786: 1084-1104F and 1618-1599R) were used to amplify the spa fragment of one isolate, which was spa negative with the standard spa primers.

\subsection{Microarray-based genotyping (Paper III)}

Isolates were characterised using the Alere Staph-Type DNA microarray (Alere Technologies, Germany) according to the manufacturer's instructions. Briefly, DNA was purified using the DNeasy Blood and Tissue kit (Qiagen, CA, USA), then amplified and labelled before 
hybridisation to a microarray containing 334 probes targeting 221 distinct genes including taxonomic, SCCmec typing, antimicrobial resistance, toxins and other virulence markers. The hybridization pattern was analysed with the respective instrument and software, and data were compiled with spa type and phenotypic antibiotic resistance results using Bionumerics v. 6.6 (Applied Maths, Belgium) to generate a graphic presentation of the distinct clades based on their genetic content.

The microarray data were also used to identify the downstream conserved segment $(d c s)$, which is a marker of the SCCmec type II remnant in isolate ECT-R2.

\subsection{Detection of SCCmec (Paper II)}

Detection of SCCmec inserted at the ISS was performed for all isolates included in Paper II using the BD GeneOhm MRSA assay (Becton Dickinson Diagnostics GeneOhm, CA, USA). The assay is a real-time PCR method for detection of MRSA directly from nasal swabs. In Paper II, however, the BD GeneOhm MRSA assay was used directly with S. aureus colonies. In brief, isolates were cultured overnight on blood agar and suspended in phosphate buffered saline (PBS) to a turbidity of $0.5 \mathrm{McF}$ arland. DNA extraction was performed using the BD GeneOhm MRSA lysis kit. SCCmec specific primers, provided by the manufacturer, were used for amplification of the genetic target by real-time PCR with a SmartCycler II instrument (Cepheid, CA, USA). For each run, a MRSA strain (CCUG 35601) and a S. aureus strain (ATCC 29213) were included as a positive and negative control, respectively. The analysis also included an internal control to monitor for the presence of inhibitors in the PCR and to confirm the integrity of assay reagents.

\subsubsection{Analysis of the SCCmec right extremity junction (Paper II and III)}

The SCCmec right extremity junction (MREJ) comprises the right extremity of SCCmec, the ISS and part of the $\operatorname{orf} X$ gene. The isolates were designated to different MREJ types according to Huletsky et al [118]. Real-time PCR was performed using one of the five different forward primers specific for SCCmec: mecii574, meciii519, meciv511, mecv492 and mecvii512, combined with reverse primer Xsau325 specific for $S$. aureus orfX, using a Rotor-Gene 3000 thermal cycler (Corbett Robotics, Australia). A molecular beacon probe (TM3orfX: 5'- 
6FAM-AGGACGTCTTACAACGYAGTAACTAYGCACT-TMR) targeting the $\operatorname{orf} X$ gene was also included. DNA was prepared as described for detection of the nuc- and mecA gene. The PCR reaction mixture consisted of $2 \mu \mathrm{L}$ of the DNA preparation together with $0.2 \mu \mathrm{M}$ of each primer, $0.25 \mu \mathrm{M}$ TM3orfX, $10 \mu \mathrm{L}$ Quantitect Probe PCR mastermix and 6.06 $\mu \mathrm{L}$ RNasefree water (Qiagen $\mathrm{AB}$, Sweden), with addition of $16 \mathrm{nmol} \mathrm{MgCl}_{2}$ in a final volume of $20 \mu \mathrm{L}$. Amplifications were performed with an initial denaturation at $95{ }^{\circ} \mathrm{C}$ for $10 \mathrm{~min}$, followed by 50 cycles of two steps consisting of denaturation at $95{ }^{\circ} \mathrm{C}$ for $15 \mathrm{sec}$, and simultaneous annealing and extension at $57{ }^{\circ} \mathrm{C}$ for $55 \mathrm{sec}$. A final cooling-step was performed for $30 \mathrm{sec}$ at $40{ }^{\circ} \mathrm{C}$. Strains representing each SCCmec type (type I: Phenotype II 43.2, type II: 07.4/0237, type III: E0898, type IV: JCSC 4744 and type V: WIS) were included as positive controls [77]. Amplicons were characterised with QIAxcel Biocalculator (Qiagen AB, Sweden).

\subsection{DNA sequencing (Paper II)}

Massive parallel 454 pyrosequencing of one isolate (ECT-R2) representing the ECT-R clone, to obtain the full genomic sequence, was performed on the Genome Sequencer FLX System (Roche, 454 Life Sciences, CT, USA) at the Norwegian High-Throughput Sequencing Centre (http://www.sequencing.uio.no) using GS FLX Titanium chemistry (Roche, 454 Life Sciences, CT, USA). Analyses using the Newbler program (Roche, 454 Life Sciences, CT, USA) were performed on the freely available Bioportal (http://www.bioportal.uio.no) at Oslo University, and edited using Sequencer 4.8 software (Gene Codes Corporation, MI, USA). The main sequence annotation was performed using the "IGS Annotation Engine" at the University of Maryland School of Medicine, USA. The Genbank nucleotide sequence accession numbers for the genome of the isolate and its two plasmids are FR714927 and FR714928-9.

\subsection{Epidemiological investigation of nosocomial transmission (Paper I and} III)

In order to delineate epidemiological relations among patients $(n=44)$ carrying the ECT-R clone (PFGE pattern A1-4 and spa type t002) included in Paper I, a retrospective epidemiological investigation was performed. By searching in the database of the clinical microbiology laboratory at Linköping University Hospital, the time and location for sampling 
of various cultures from each patient could be identified. This made it possible to determine in which hospital department or primary care centre the patient had received care. Locations where two or more patients had been admitted in the same month were considered a focus for potential nosocomial transmission, and were further analysed. In addition to the genetically investigated isolates, special note was made of other findings of ECT-R MSSA. The time period studied was approximately six months before, to one year after the date of isolation of the genetically investigated isolate. The database search period extended until February 2008, and thus patients with a genetically investigated isolate found later than February 2007 were studied for less than a year after isolation of that isolate.

In Paper III, an epidemiological investigation was performed for patients with isolates designated t084, since these isolates met the inclusion criteria of being found in two or more counties with two or more isolates per county. To avoid the risk of missing any related isolates, isolates with related spa types belonging to the same CC (i.e. CC15) according to the microarray results were also included in the investigation. Co-workers at the local clinical microbiological laboratory of each county collected information about each patient possibly involved in the transmission event, including the patient's social security number, and the time and location for sampling of various cultures. The information was then sent to coworkers at the local clinical microbiological laboratory in the neighbouring counties, where a search in the database of the clinical microbiology laboratory was performed to determine whether these patients had been sampled at any site within another county than their own. 


\section{Results}

\subsection{Paper I}

Between January 2004 and October 2007, 54 ECT-R MSSA isolates from 49 patients were collected at the clinical microbiology laboratory at Linköping University Hospital. All isolates were confirmed as ECT-R by antibiotic susceptibility testing, with MIC values of $>256 \mathrm{mg} / \mathrm{L}$ against erythromycin and clindamycin, and a range of 24 to $>256 \mathrm{mg} / \mathrm{L}$ against tobramycin. Three $(6 \%)$ of the isolates were resistant to fusidic acid, none $(0 \%)$ to rifampicin, four $(7 \%)$ to gentamicin and $50(93 \%)$ to moxifloxacin.

PFGE showed that $37(69 \%)$ isolates were considered clonal according to the criteria proposed by Tenover et al. [101], and were designated pattern A1. This pattern represented the outbreak clone. In addition, twelve isolates ( $22 \%$ ) differed from the ECT-R clone by one to two bands, and were considered closely related (patterns A2, A3 and A4). Thus, a total of $49(91 \%)$ isolates was considered to be part of the clonal outbreak (Table 4). The exact same $91 \%$ were designated spa type t002 (Figure 1). Neither the two MRSA isolates (t032 and t149) isolated during the MRSA outbreak in 2005, nor the three MRSA isolates designated t002 from Östergötland County, showed any relatedness with the ECT-R clone when typed with PFGE. However, the MRSA isolate from SMI (t088) differed by just four bands, and was considered possibly related (pattern A6). None of the susceptible isolates were designated t002. However, two isolates yielded patterns similar to the ECT-R clone when typed with PFGE. One of these isolates differed by two bands and was considered closely related (pattern A5), whereas the other one differed by five bands and was considered possibly related (pattern A7). All isolates except one were shown to be negative when analysed for presence of PVL genes. However, this isolate was designated not defined (ND) when analysed with PFGE and spa typing (Table 4).

Among the 44 patients carrying the ECT-R clone, 41 patients were suspected to be part of a transmission event (i.e. admitted to the same location during the same month as at least one patient with previous or subsequent infection with the clone). At most of the hospital departments and primary care centres included in the investigation only single cases were found, with no indication of further transmission. However, two or more patients were admitted during the same month to each of eight hospital departments at Linköping University Hospital and two primary care centres in the city of Linköping. The transmission event probably emerged at hospital department 4 , where eight patients, of whom five carried ECT-R 
MSSA, were admitted on different occasions between March and August 2005. The ECT-R clone was probably further transmitted to the other locations by one or more of these patients (Table 5).

Table 4: PFGE pattern, spa type and incidence of PVL.

\begin{tabular}{|c|c|c|c|c|}
\hline No. of isolates & Antibiotic resistance profile & PFGE pattern & spa type & PVL \\
\hline 37 & ECT-R MSSA & A1 & t002 & - \\
\hline 1 & ECT-R MSSA & A2 & $\mathrm{t} 002$ & - \\
\hline 1 & ECT-R MSSA & A3 & t002 & - \\
\hline 10 & ECT-R MSSA & A4 & $\mathrm{t} 002$ & - \\
\hline 1 & ECT-S MSSA & A5 & $\mathrm{t} 548$ & - \\
\hline 1 & MRSA (SMI) & A6 & t088 & - \\
\hline 1 & ECT-S MSSA & A7 & $\mathrm{t} 1084$ & - \\
\hline 1 & ECT-R MSSA & $\mathrm{B}$ & $\mathrm{t} 149$ & - \\
\hline 1 & ECT-S MSSA & $\mathrm{C}$ & t056 & - \\
\hline 1 & ECT-R MSSA & $\mathrm{D}$ & t796 & - \\
\hline 1 & ECT-S MSSA & E1 & $\mathrm{t} 346$ & - \\
\hline 2 & ECT-S MSSA & E2 & $\mathrm{t} 084$ & - \\
\hline 1 & ECT-S MSSA & E3 & $\mathrm{t} 279$ & - \\
\hline 1 & ECT-S MSSA & $\mathrm{E} 4$ & $\mathrm{t} 3225$ & - \\
\hline 1 & ECT-S MSSA & $\mathrm{F}$ & $\mathrm{t} 449$ & - \\
\hline 1 & ECT-S MSSA & $\mathrm{G}$ & $\mathrm{t} 246$ & - \\
\hline 1 & ECT-S MSSA & $\mathrm{H}$ & $\mathrm{t} 160$ & - \\
\hline 1 & ECT-R MSSA & I & $\mathrm{t} 3025$ & - \\
\hline 1 & ECT-S MSSA & $\mathrm{J}$ & $\mathrm{t} 127$ & - \\
\hline 1 & ECT-S MSSA & $\mathrm{K}$ & $\mathrm{t} 189$ & - \\
\hline 1 & ECT-S MSSA & $\mathrm{L}$ & $\mathrm{t} 267$ & - \\
\hline 1 & ECT-S MSSA & M & t3397 & - \\
\hline 1 & ECT-S MSSA & $\mathrm{N}$ & $\mathrm{t} 172$ & - \\
\hline 1 & ECT-S MSSA & $\mathrm{N}$ & $\mathrm{t} 216$ & - \\
\hline 1 & ECT-S MSSA & $\mathrm{O}$ & $\mathrm{t} 487$ & - \\
\hline 1 & ECT-S MSSA & P1 & t3396 & - \\
\hline 1 & ECT-R MSSA & $\mathrm{P} 2$ & $\mathrm{t} 021$ & - \\
\hline 1 & ECT-S MSSA & P3 & $\mathrm{t} 021$ & - \\
\hline 1 & MRSA (outbreak) & Q & $\mathrm{t} 032$ & - \\
\hline 1 & MRSA (outbreak) & $\mathrm{R}$ & $\mathrm{t} 149$ & - \\
\hline 1 & MRSA (t002) & S & t002 & - \\
\hline 1 & MRSA (t002) & $\mathrm{T}$ & t002 & - \\
\hline 1 & MRSA (t002) & $\mathrm{U}$ & t002 & - \\
\hline 1 & ECT-R MSSA & ND & ND & + \\
\hline
\end{tabular}




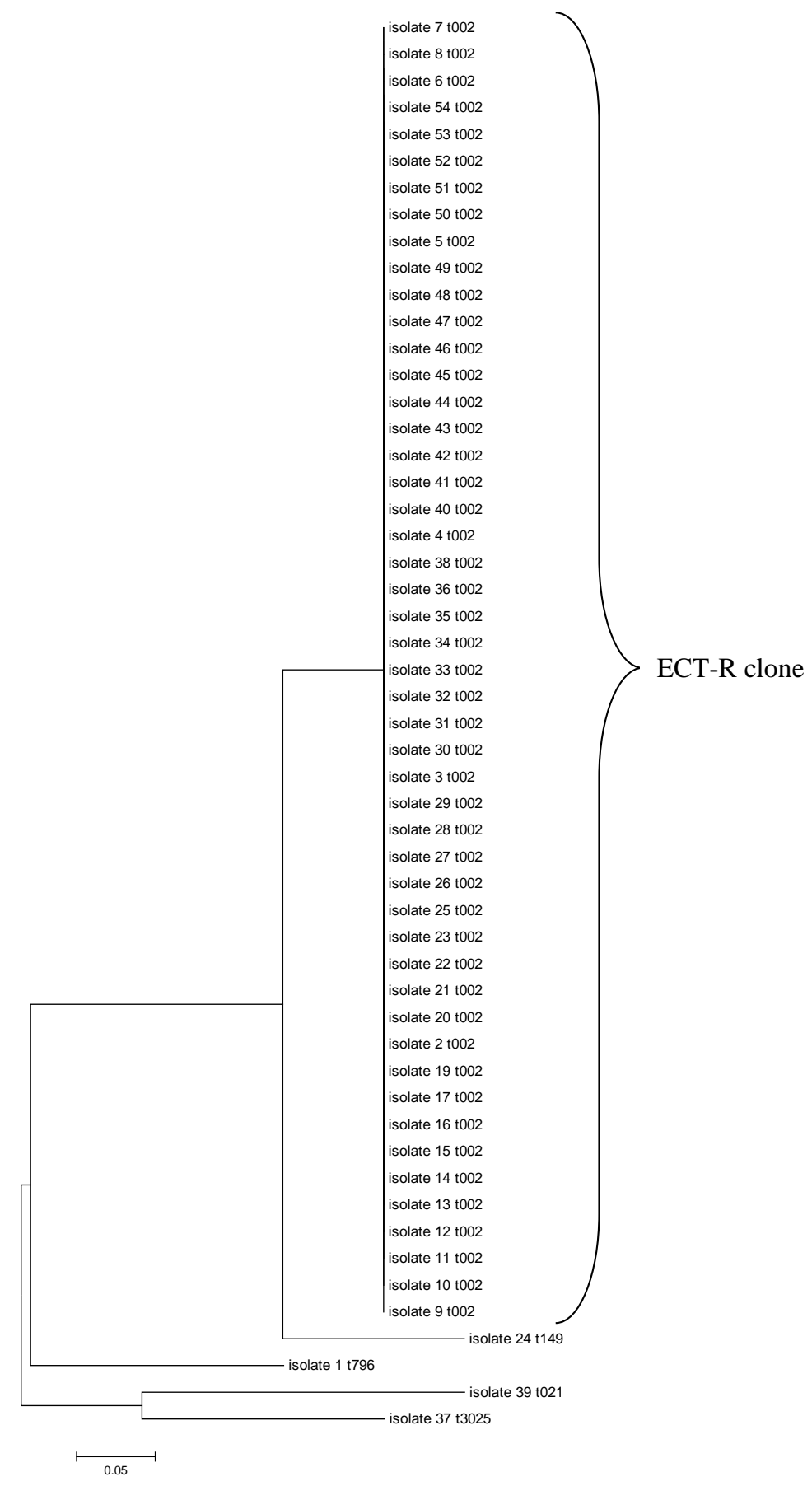

Figure 1: Phylogenetic neighbour-joining tree based on spa type and corresponding spa cluster of ECT-R MSSA isolates. 


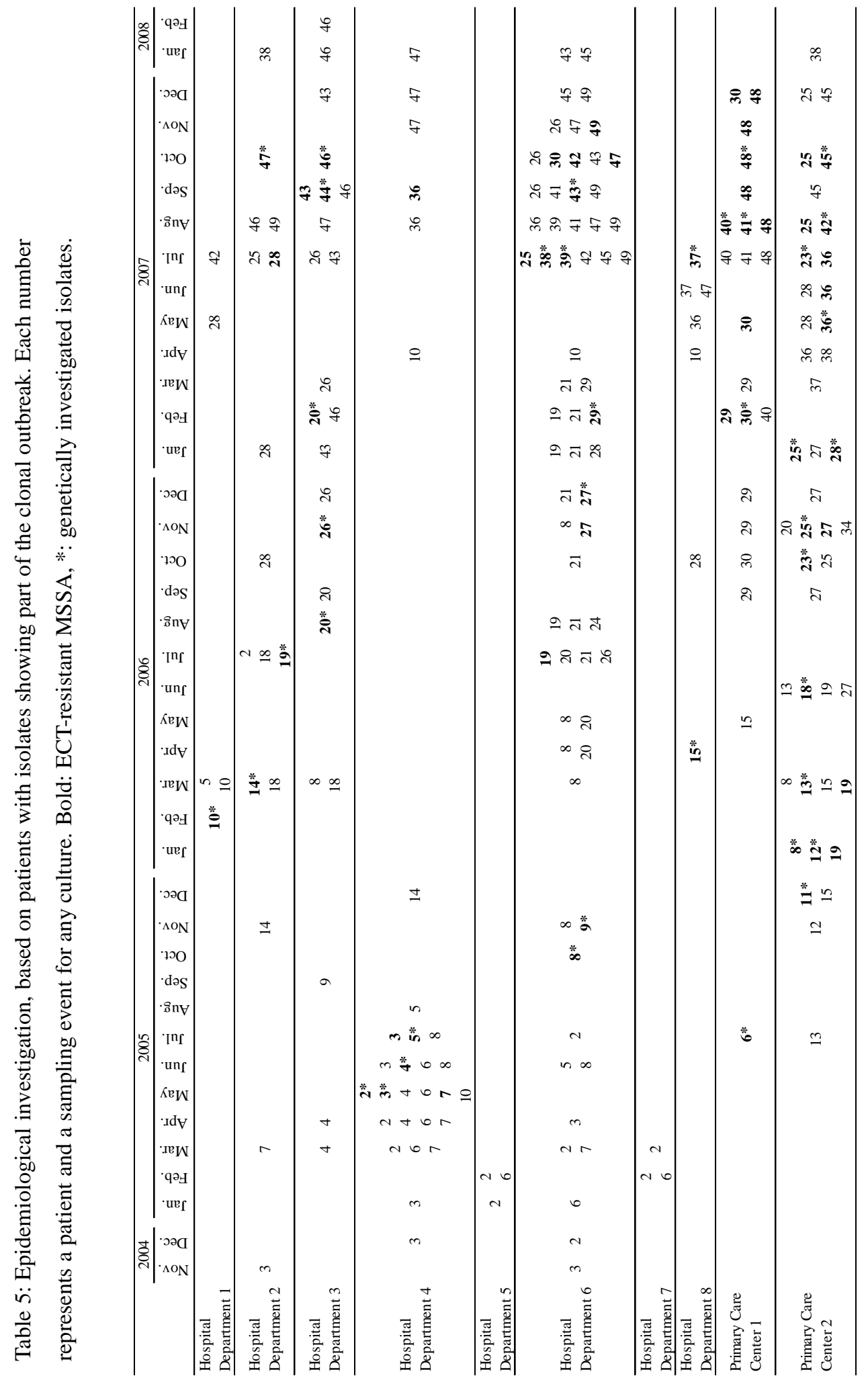




\subsection{Paper II}

All of the 54 ECT-R MSSA isolates were determined to be PCR positive for the nuc gene and negative for the mecA gene.

Detection of SCCmec according to the BD GeneOhm MRSA assay identified 50 positive samples $(93 \%)$, including all isolates of the ECT-R clone $(n=49)$ and one additional isolate with PFGE pattern B. When PCR was performed separately with the five forward primers specific for SCCmec, only mecii574 in combination with reverse primer Xsau325 allowed amplification. A PCR product was found in 51 isolates, including all 50 isolates identified as positive with the BD GeneOhm MRSA assay and one additional isolate previously identified as negative (PFGE pattern D). Primer mecii574 recognizes the right extremity sequences of SCCmec type I, II, IVa, b and c. The right extremities of SCCmec type II, IVa, b and c (represented by MREJ type ii) are identical and differ only from the right extremity of SCCmec type I (represented by MREJ type i) by a 102 bp insertion [118]. When further analysed, the amplicon size was shown to be approximately $278 \mathrm{bp}$ for all isolates of the ECT-R clone. This suggested that these isolates were MREJ type ii. The two remaining isolates had an amplicon size of $176 \mathrm{bp}$, and were designated MREJ type i (Table 6).

The nucleotide sequence of isolate ECT-R2, representing the ECT-R clone, showed carriage of a pseudo-SCC element estimated to be $12 \mathrm{~kb}$ in size. A Blast search of this pseudo-SCC DNA against nucleotide databases revealed a close relationship with parts of the SCCmec type II element of MRSA strain N315 (Genbank accession no. D86934). This strain is named the New York/Japan clone and belongs to MLST CC5. Alignment of the pseudoSCC DNA with the SCCmec type II element using the CLC Sequence Viewer, version 6.0.2 (CLC bio, Denmark), showed an identical genomic organisation except a $41 \mathrm{~kb}$ gap in isolate ECT-R2 compared to strain N315. The pseudo-SCC element and the SCCmec type II element were identical in SCCmec bp 1 to 8354. The large excised region was located between bp 8355 and 49295 in the SCCmec element of strain N315, and included the entire $c c r$ - and mec gene complex, transposon Tn554 (carrying the ermA gene), and characteristic genes such as the $k d p$ operon. However, the ant(4') gene was conserved. The remaining region of the pseudo-SCC element (N315 SCCmec bp 49296-58237) only included five single nucleotide substitutions (bp 50119, 50518, 54171, 54204 and 55662) (Figure 2). An ermA gene was found outside the pseudo-SCC element and was located between bp 146968 and 147699 in the ECT-R2 genome (Genbank accession no. FR714927). The nucleotide sequence of isolate 
ECT-R2 was also compared to the SCCmec type IVa element of S. aureus strain cm11 (Genbank accession no. EU437549), which is known to carry pUB110, but showed no similarity, and SCCmec type IVa was thereby rejected as a possible origin.

All isolates of the ECT-R clone were shown to carry the ermA- and ant( $\left.4^{\prime}\right)$ gene with conventional PCR. The ermA gene was also identified in the isolate designated PFGE pattern B (Table 6).

Table 6: Incidence of SCCmec remnant, designated MREJ type, and incidence of the ermA- and ant(4')gene.

\begin{tabular}{lllllll}
\hline No. of isolates & PFGE pattern $^{1}$ & spa type $^{1}$ & SCCmec & MREJ type & $\operatorname{ermA}^{2}$ & $\operatorname{ant}\left(4^{\prime}\right)^{2}$ \\
\hline 49 & A1-4 & t002 & + & ii & + & + \\
1 & B & $\mathrm{t} 149$ & + & i & + & - \\
1 & D & t796 & - & i & - & - \\
\hline 1 & I & t3025 & - & - & \\
1 & P2 & t021 & - & - & \\
1 & ND & ND & - & - & \\
\hline
\end{tabular}

${ }^{1}$ Previously analysed in Paper I.

${ }^{2}$ One isolate from each group of ECT-R MSSA with different PFGE patterns and that were positive in the MREJ analysis was analysed regarding ermA and ant(4'). 


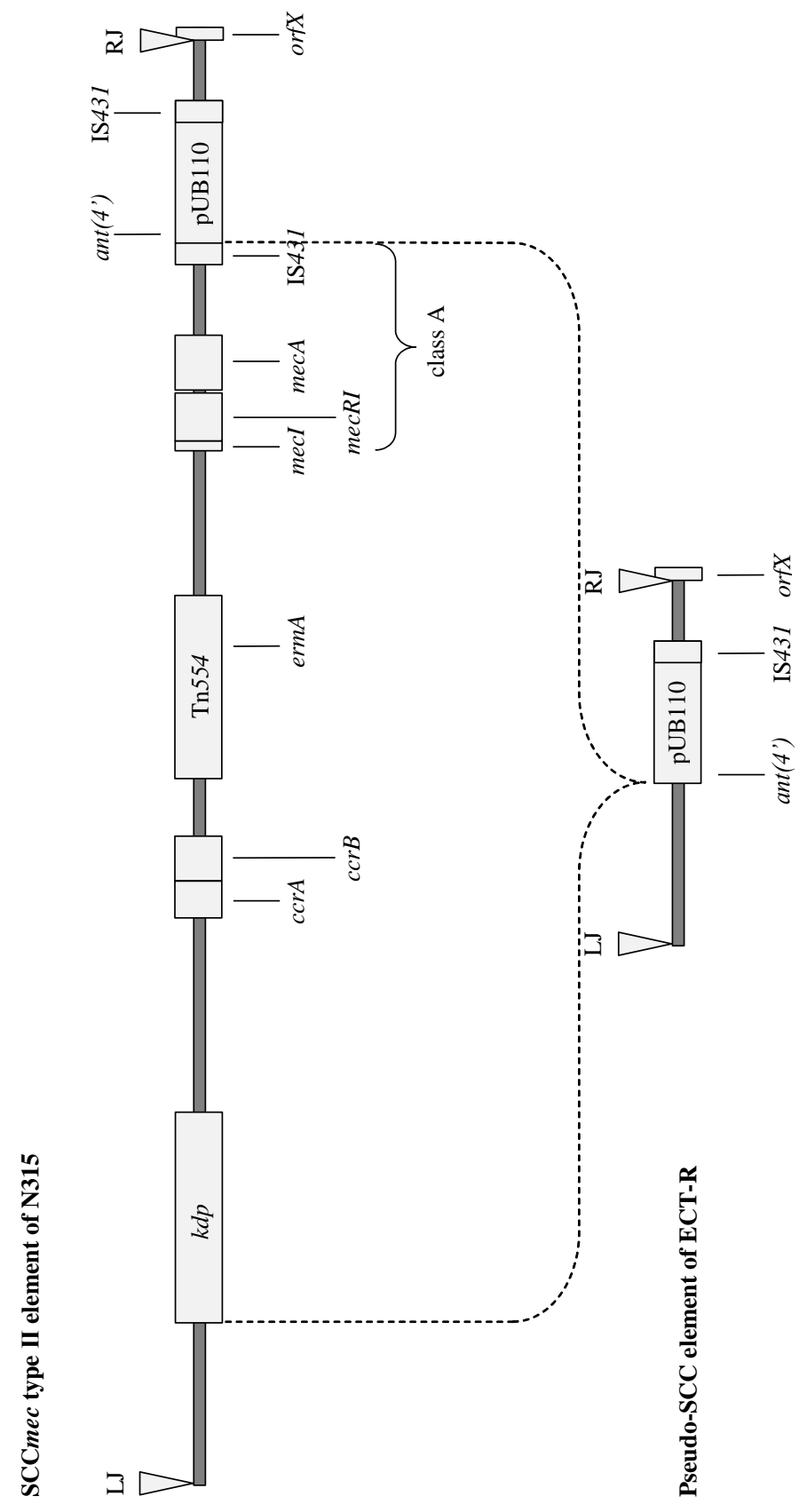

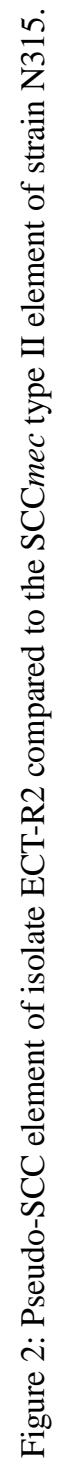




\subsection{Paper III}

Between June 2009 and June 2010, a total of 100 clinical isolates of S. aureus with the defined antibiotic resistance profiles were collected from the three County Councils in southeast Sweden. However, two isolates were shown to be resistant to cefoxitin and positive for the $m e c A$ gene, i.e. MRSA, and were thereby excluded from further analyses. This resulted in 98 isolates, including 42 isolates with clindamycin-resistance (group 1), 42 isolates with tobramycin-resistance (group 2), and 14 isolates with resistance to both clindamycin and tobramycin (group 3). Jönköping County included eleven, 15 and one isolate belonging to group 1, 2 and 3, respectively, whereas the corresponding figures for Kalmar County were 13, ten and one and for Östergötland County 18, 19 and twelve isolates, respectively.

All clindamycin-resistant isolates (group 1) had MIC values of $>256 \mathrm{mg} / \mathrm{L}$, except one isolate with a MIC of $12 \mathrm{mg} / \mathrm{L}$. The tobramycin-resistant isolates (group 2) had MIC values from 4 to $128 \mathrm{mg} / \mathrm{L}$. All isolates in group 3 showed resistance to clindamycin (MIC >256 $\mathrm{mg} / \mathrm{L}$ ) and tobramycin (MIC range: 1.5 to $>256 \mathrm{mg} / \mathrm{L}$ ). In addition, $93 \%$ of the isolates in group 3 showed resistance to moxifloxacin. Multi-resistance (i.e. resistance to two or more classes of non-beta-lactam antibiotics) was $21 \%$ in group 1, $12 \%$ in group 2 and $100 \%$ in group 3 (Table 7).

The isolates were designated as 39 different spa types. Whereas no specific spa type dominated in group 1, t084 was commonly found among the isolates in group 2 in all three counties (Jönköping: $80 \%$, Kalmar: $50 \%$ and Östergötland: $47 \%$ ). Resistance to both clindamycin and tobramycin (group 3) was rare, except in Östergötland County, where all of these isolates $(\mathrm{n}=12)$ were designated t002. This spa type was also found among three additional isolates belonging to group 1 (two from Östergötland County and one from Kalmar County). The isolate which was spa negative with the standard spa primers was designated t13024 with the alternative spa primers (Table 7).

When PCR was performed separately with the five forward primers specific for SCCmec, only mecii574 in combination with reverse primer Xsau325 allowed amplification. A PCR product was found in 15 isolates $(15 \%)$. These isolates were all collected in Östergötland County, including all twelve isolates in group 3 (t002) and three isolates belonging to group 1 (of which two were designated t002, and the remaining one t091). When further analysed, the amplicon size was shown to be $176 \mathrm{bp}$ for one isolate (t091). This suggested that this isolate 
was MREJ type i. The remaining 14 isolates (t002) had an amplicon size of $278 \mathrm{bp}$, and were designated MREJ type ii.

The microarray analysis categorised the isolates into 17 different $\mathrm{CC}$-clades, including the four larger clades CC5 $(n=17), \operatorname{CC} 15(n=30), \operatorname{CC} 30(n=12)$ and CC45 $(n=14)$. CC5 included all 15 isolates designated t002, isolate ECT-R2 and one additional isolate of spa type t458 belonging to group 1, which was collected in Östergötland County. The Q9XB68-dcs gene was present in 15 of the 17 isolates belonging to CC5, including all isolates of spa type t002 collected in Östergötland County $(\mathrm{n}=14)$ and isolate ECT-R2. In contrast, $d c s$ was absent from the remaining 83 isolates. CC15 included all isolates in group 2 designated t084 $(n=25)$ and five additional isolates (t084, t094, t436, t674 and t6684) (Figure 3, Table 7). A high incidence $(60 \%)$ of the isolates belonging to $\mathrm{CC} 15$ was collected from newborns, with $94 \%$ sharing spa type t084, indicating inter-hospital transmission, although this could not be proved with the epidemiological investigation. 
Table 7: Antibiotic susceptibility in relation to CC and spa type. EM: erythromycin, CM:

clindamycin, TM: tobramycin, GM: gentamicin, FU: fusidic acid, RI: rifampicin, MX:

moxifloxacin, VA: vancomycin, FOX: cefoxitin. Black shading: 75-100 \% resistance $(I+R)$, grey shading: $25-75 \%$ resistance $(\mathrm{I}+\mathrm{R})$.

\begin{tabular}{|c|c|c|c|c|c|c|c|c|c|c|c|}
\hline $\mathrm{CC}$ & spa type & No. of isolates & EM & $\mathrm{CM}$ & TM & GM & FU & RI & MX & VA & FOX \\
\hline \multirow[t]{2}{*}{ CC5 } & t002 & 15 & 15 & 15 & 12 & 1 & 1 & 0 & 14 & 0 & 0 \\
\hline & $\mathrm{t} 458$ & 1 & 1 & 1 & 0 & 0 & 0 & 0 & 0 & 0 & 0 \\
\hline \multirow[t]{2}{*}{$\mathrm{CC} 7$} & t091 & 1 & 1 & 1 & 0 & 0 & 0 & 0 & 0 & 0 & 0 \\
\hline & t796 & 1 & 1 & 1 & 1 & 1 & 0 & 0 & 0 & 0 & 0 \\
\hline $\mathrm{CC} 8$ & $\mathrm{t} 148$ & 1 & 1 & 1 & 0 & 0 & 0 & 0 & 0 & 0 & 0 \\
\hline $\mathrm{CC} 12$ & $\mathrm{t} 160$ & 2 & 0 & 0 & 2 & 0 & 0 & 0 & 0 & 0 & 0 \\
\hline \multirow[t]{5}{*}{$\mathrm{CC} 15$} & t084 & 26 & 1 & 1 & 25 & 1 & 0 & 0 & 0 & 0 & 0 \\
\hline & t094 & 1 & 1 & 1 & 0 & 0 & 0 & 0 & 0 & 0 & 0 \\
\hline & $\mathrm{t} 436$ & 1 & 0 & 0 & 1 & 0 & 0 & 0 & 0 & 0 & 0 \\
\hline & t674 & 1 & 0 & 0 & 1 & 0 & 1 & 0 & 0 & 0 & 0 \\
\hline & t6684 & 1 & 1 & 1 & 0 & 0 & 0 & 0 & 0 & 0 & 0 \\
\hline \multirow[t]{2}{*}{$\mathrm{CC} 20$} & t996 & 1 & 1 & 1 & 0 & 0 & 0 & 0 & 0 & 0 & 0 \\
\hline & t2919 & 1 & 1 & 1 & 0 & 0 & 1 & 0 & 0 & 0 & 0 \\
\hline \multirow[t]{2}{*}{$\mathrm{CC} 22$} & t005 & 3 & 3 & 1 & 2 & 2 & $\overline{0}$ & 0 & 2 & 0 & 0 \\
\hline & $\mathrm{t} 13024$ & 1 & 0 & 0 & 1 & 1 & 0 & 0 & 0 & 0 & 0 \\
\hline \multirow[t]{6}{*}{$\mathrm{CC} 30$} & $\mathrm{t} 012$ & 1 & 0 & 0 & 1 & 1 & 0 & 0 & 0 & 0 & 0 \\
\hline & $\mathrm{t} 021$ & 2 & 1 & 1 & 1 & 0 & 0 & 0 & 0 & 0 & 0 \\
\hline & t089 & 6 & 6 & 6 & 0 & 0 & 0 & 0 & 0 & 0 & 0 \\
\hline & $\mathrm{t} 122$ & 1 & 1 & 1 & 0 & 0 & 0 & 0 & 0 & 0 & 0 \\
\hline & $\mathrm{t} 166$ & 1 & 0 & 0 & 1 & 0 & 0 & 0 & 0 & 0 & 0 \\
\hline & $\mathrm{t} 884$ & 1 & 1 & 1 & 0 & 0 & 0 & 0 & 0 & 0 & 0 \\
\hline \multirow[t]{8}{*}{$\mathrm{CC} 45$} & t073 & 2 & 2 & 2 & 0 & 0 & 0 & 0 & 0 & 0 & 0 \\
\hline & $\mathrm{t} 230$ & 1 & 1 & 1 & 0 & 0 & 0 & 0 & 0 & 0 & 0 \\
\hline & $\mathrm{t} 302$ & 1 & 0 & 0 & 1 & 0 & 0 & 0 & 0 & 0 & 0 \\
\hline & $\mathrm{t} 722$ & 1 & 1 & 1 & 0 & 0 & 0 & 0 & 0 & 0 & 0 \\
\hline & $\mathrm{t} 728$ & 6 & 6 & 6 & 0 & 0 & 0 & 0 & 6 & 0 & 0 \\
\hline & $\mathrm{t} 2614$ & 1 & 1 & 1 & 0 & 0 & 0 & 0 & 0 & 0 & 0 \\
\hline & t8560 & 1 & 1 & 1 & 0 & 0 & 0 & 0 & 0 & 0 & 0 \\
\hline & $\mathrm{t} 8561$ & 1 & 1 & 1 & 0 & 0 & 0 & 0 & 0 & 0 & 0 \\
\hline CC50 & $\mathrm{t} 705$ & 1 & 1 & 1 & 0 & 0 & 0 & 0 & 0 & 0 & 0 \\
\hline CC59 & $\mathrm{t} 441$ & 1 & 1 & 1 & 0 & 0 & 0 & 0 & 0 & 0 & 0 \\
\hline CC88 & $\mathrm{t} 4385$ & 1 & 0 & 0 & 1 & 0 & 0 & 0 & 0 & 0 & 0 \\
\hline CC101 & $\mathrm{t} 524$ & 2 & 2 & 2 & 0 & 0 & 0 & 0 & 0 & 0 & 0 \\
\hline CC121 & t2092 & 1 & 1 & 1 & 0 & 0 & 0 & 0 & 0 & 0 & 0 \\
\hline \multirow[t]{3}{*}{ CC188 } & t065 & 1 & 0 & 0 & 1 & 1 & 0 & 0 & 0 & 0 & 0 \\
\hline & $\mathrm{t} 189$ & 2 & 1 & 1 & 2 & 1 & 0 & 0 & 1 & 0 & 0 \\
\hline & $\mathrm{t} 8562$ & 1 & 0 & 0 & 1 & 0 & 0 & 0 & 0 & 0 & 0 \\
\hline \multirow[t]{2}{*}{ CC398 } & t011 & 1 & 1 & 1 & 0 & 0 & 0 & 0 & 0 & 0 & 0 \\
\hline & t034 & 3 & 3 & 1 & 2 & 2 & 0 & 0 & 0 & 0 & 0 \\
\hline ST426 & $\mathrm{t} 1715$ & 1 & 0 & 1 & 0 & 0 & 0 & 0 & 0 & 0 & 0 \\
\hline
\end{tabular}




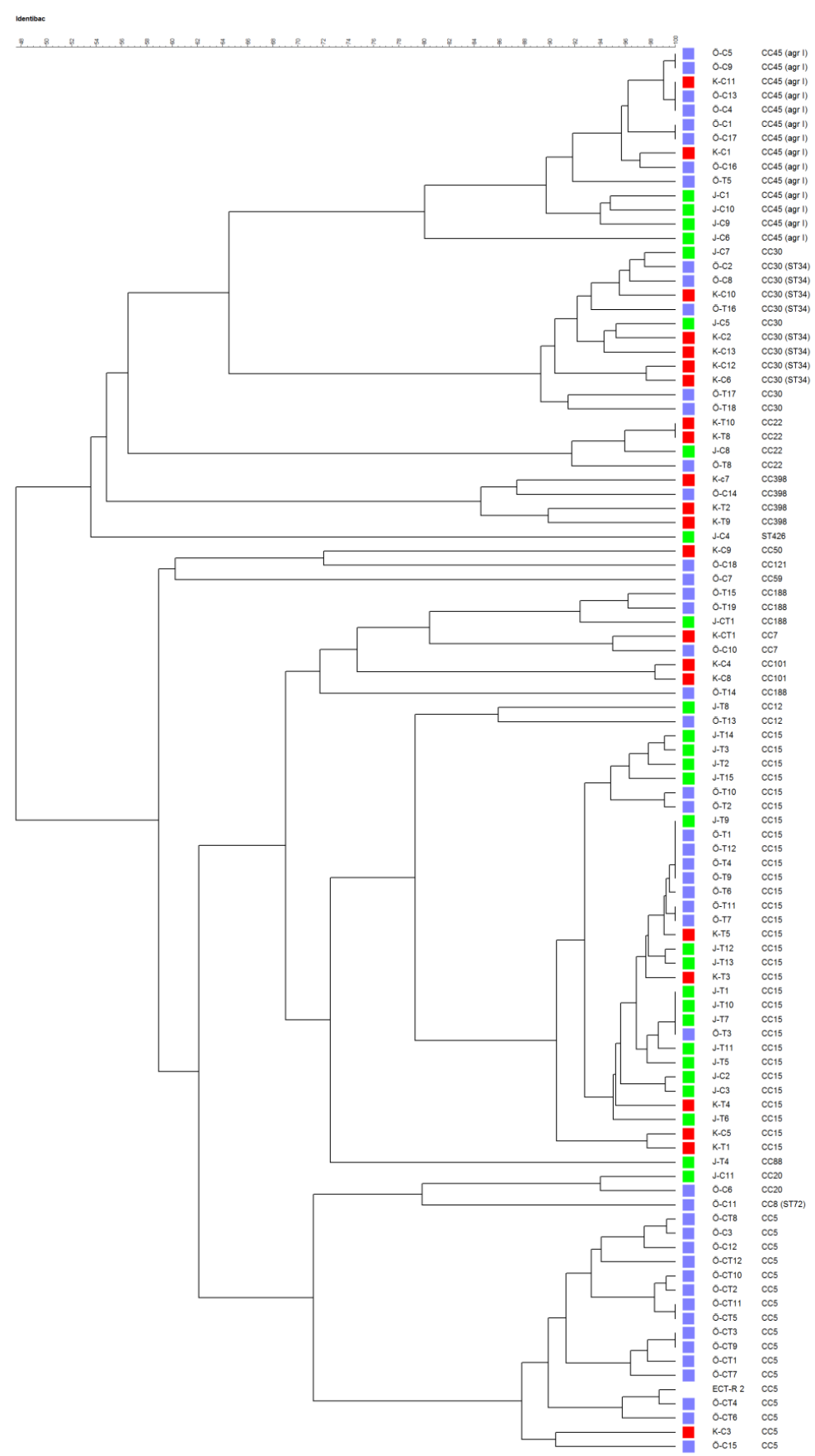

Figure 3: Dendrogram based on microarray results, showing the branching of the various clades according to the content of genetic markers. Green: isolates from Jönköping County, red: isolates from Kalmar County, blue: isolates from Östergötland County. 


\section{Discussion}

This thesis investigated the high incidence of MSSA with concomitant resistance to erythromycin, clindamycin and tobramycin (ECT-R) detected in Östergötland County, Sweden, and possible transmission to the neighbouring counties (Jönköping- and Kalmar County) in southeast Sweden with whose hospitals a high exchange of patients occurs. The ECT-R MSSA strain was first detected in 2005, in parallel with a major outbreak of MRSA caused by two strains designated spa type t032 and t149. According to a search in the database of the clinical microbiology laboratory at Linköping University Hospital, the incidence of ECT-R MSSA in Östergötland County ranged between $0.03 \%$ and $0.82 \%$ during 2004 to 2013, with a peak in 2007. In contrast to MRSA, little information is available regarding clonal distribution of MSSA. However, a few outbreaks caused by MSSA have recently been reported [119-121].

In Paper I, analysis showed that $91 \%$ (49/54) of the investigated ECT-R MSSA isolates from Östergötland County belonged to PFGE pattern A, which included four different but closely related patterns (A1-4), and were designated spa type t002. These isolates were considered to be part of the clonal outbreak. No relatedness could be shown with either of the two MRSA strains that were transmitted during the MRSA outbreak, or with other t002 strains found in Östergötland County. In Paper III, three groups of MSSA with different antibiotic resistance profiles, including the ECT-R profile, were collected from the three County Councils in southeast Sweden. The ECT-R resistance profile was shown to be rare, except in Östergötland County where all of these isolates $(n=12)$ were designated t002. This spa type was also found among two additional isolates from Östergötland County belonging to another antibiotic resistance profile-group. spa type t002 is one of the most frequently occurring spa types worldwide among both MRSA and MSSA, and is associated with pandemic clones such as the New York/Japan-, Pediatric- and USA100 clone. These clones have been classified as part of CC5 with MLST [4, 122-123]. This spa type is also common in Sweden, as shown by Petersson et al. [124], who found that t002 was the second most common spa type when typing 216 MRSA isolates from a low-prevalence region in Sweden. More recently, in a study by Larsson et al. [125] t002 proved to be one of the most predominant spa types among 1788 MRSA isolates collected from patients in a Swedish county. To my knowledge, the prevalence of spa type t002 among MSSA in Sweden has not previously been studied. All twelve isolates with the ECT-R resistance profile and the two additional isolates of spa type t002 from Östergötland County included in Paper III were 
considered to belong to CC5 by microarray analysis, and were thus, with a high degree of certainty, believed to be descendants of the ECT-R clone.

Multi-resistant MSSA may be derived from a highly successful MRSA strain, which partially excised its SCCmec. There are a number of currently available methods for the characterisation of SCCmec [78, 126-129]. However, since these methods are based on the presence of the $c c r$-and/or mec gene complex they are not applicable on strains carrying SCCmec remnants, in which these gene complexes may have been partially or fully excised. In Paper II, two different methods targeting the ISS and the MREJ, respectively, were used for detection of SCCmec. All isolates of the ECT-R clone $(n=49)$ were shown to carry SCCmec remnants with both methods, and were designated MREJ type ii. Similarly, the isolates included in Paper III were analysed with MREJ typing, which showed that all 14 isolates of the ECT-R clone were designated MREJ type ii. Using SCCmec-specific primers separately may be more discriminating compared to a multiplex method, as shown in Paper II, where one isolate identified as negative with the BD GeneOhm MRSA assay was PCRpositive with primer pair mecii574/Xsau325, and designated MREJ type i. The BD GeneOhm MRSA assay is one of several commercially available MRSA assays that use real-time PCR for detection of SCCmec. However, these tests do not specifically target the mecA gene, which may result in many false-positive isolates, probably due to the presence of SCCmec remnants or SCC sequences. This has been shown in a number of studies, where the reported MRSA isolates were actually MSSA [118, 130-132]. The BD GeneOhm MRSA assay has also been shown to be unable to detect MRSA isolates. In a Danish study by Bartels et al. [133], 44 MRSA isolates, including the most common clone in Copenhagen, were undetectable with the BD GeneOhm MRSA assay. The representative isolate of the ECT-R clone carried a pseudo-SCC element estimated to be $12 \mathrm{~kb}$ in size, showing a resemblance of more than $99 \%$ with the SCCmec type II element of MRSA strain N315 (New York/Japan clone, MLST CC5). In addition to the entire $c c r$ - and mec gene complex, the excised region included transposon Tn554 carrying the ermA gene. However, ermA was found to be located outside the pseudo-SCC element. This was in accordance with both the conventional PCR results (Paper I) and the microarray analysis (Paper III), which identified all isolates of the ECT-R clone as ermA-positives. Multiple copies of ermA in S. aureus have been described in a study by Kuroda et al. [134], where whole genome sequencing of strain N315 showed that in addition to one copy of Tn554 found in SCCmec, four other copies were located in the genome outside the SCCmec element. The microarray analysis performed in Paper III showed 
that all isolates of the ECT-R clone carried the Q9XB68-dcs gene, which was used as a marker of the SCCmec type II remnant in the representative isolate of the ECT-R clone that was previously whole genome sequenced as described in Paper II. Only a few previous studies have identified multi-resistant MSSA carrying remnants of SCCmec. In a study from France, SCCmec remnants were found in $68 \%$ of the investigated isolates that were predominantly part of MLST CC5 or CC8 [76]. A similar study from Ireland resulted in a $28 \%$ rate of MRSA-derived MSSA isolates, also part of CC5 or CC8 [77]. The latter study was the first one presenting a detailed description of a SCCmec remnant in MSSA. Similar to Paper II, Wong et al. [135] described the entire nucleotide sequence of pseudo-SCC elements resembling SCCmec type II in seven MSSA USA100 strains (spa type t002, MLST CC5). Interestingly, and very similar to our finding, in two of the four isolates described, the internal deletions terminated at IS431 sequences at the very same nucleotide (nt 49295) of the $3^{\prime}$ border, underscoring the role of IS elements in the deletion events in SCCmec type II. It has been shown that MRSA patients may also carry genotypically identical MSSA isolates, except for the absence of SCCmec, indicating spontaneous excision of SCCmec [136-137]. Spontaneous excision of mecA, causing MSSA to emerge from MRSA both in vivo and in vitro, has been described in several other studies [138-140]. This phenomenon may be due to stressful conditions in vitro, such as long-term storage in antibiotic-free medium, nutrient starvation, elevated temperatures or UV radiation [138, 141-142]. Furthermore, prolonged therapy with non- $\beta$-lactam antibiotics and exposure to vancomycin can be contributing factors, resulting in partial excision of SCCmec [140].

Moxifloxacin-resistance also proved to be characteristic of the ECT-R clone. Testing for susceptibility against this antibiotic was not routinely conducted by the clinical microbiology laboratory at Linköping University Hospital during the study period, and thus was not included in the original search in the database for multi-resistant MSSA, which was designed based on an increase of concomitant resistance to clindamycin, erythromycin and tobramycin. Fluoroquinolone-resistance is considered to be a likely marker for successful HA-MRSA clones. The major pandemic clones are resistant, including CC5, CC22, CC30, CC45 and ST239 [143-145]. In a study by Lindsay [40], an extremely strong correlation between resistance to fluoroquinolone and methicillin was shown, but only in successful HA-MRSA clones and not in sporadic MRSA strains that are not easily transmitted. Restrictions in the prescribing of fluoroquinolones may result in a decrease in MRSA [146-148], whereas reintroduction makes MRSA rise again [149]. In a cross-sectional study by den Heijer et al. 
[150], concerning prevalence and resistance of commensal S. aureus in nine European countries, multi-resistance was shown to be most common in the UK (3\%) and least common in Sweden $(0.2 \%)$. The antibiotics tested for were azithromycin, ciprofloxacin, clindamycin, daptomycin, erythromycin, gentamicin, linezolid, oxacillin, penicillin, tetracycline, cotrimoxazole and vancomycin.

The epidemiological investigation performed for patients carrying the ECT-R clone in Paper I showed that the clonal outbreak was concentrated in eight hospital departments and two primary care centres, all located in the city of Linköping. However, other locations could have been involved in the transmission event, since not all ECT-R MSSA isolates had been saved by the clinical microbiology laboratory, and thus were unavailable for genotyping and subsequent epidemiological investigation. The majority of the isolates of the ECT-R clone were collected from elderly patients with wound infections. This patient profile was in accordance with the patients carrying the ECT-R clone included in Paper III. One possible explanation for why the ECT-R clone had not been transmitted to the neighbouring counties in southeast Sweden, may have been that patients from Jönköping- and Kalmar County referred to Linköping University Hospital are not cared for at the same departments in which patients typically infected with the clone are located. Thus, the likelihood of these patients meeting, and subsequent possible transmission of the ECT-R clone occurring, was very low. Compared to its connected hospitals, a tertiary care hospital such as Linköping University Hospital is more likely to have outbreaks of nosocomial infection because of the severity of underlying medical conditions among the patients, higher antibiotic use, and frequency of invasive procedures. In addition, a tertiary care hospital admits more patients referred from other hospitals, where they might have been colonized with pathogens [151]. Infection control workers have visited the affected hospital departments and primary care centres in order to enhance implementation of basic hygiene guidelines, and to stop further transmission. No routinely performed screening for carriers has been performed. However, a strategy of generous sampling for cultivation on clinical indication was encouraged at these locations, which may have increased the number of ECT-R MSSA isolates found in patients admitted to these locations. The infection control efforts were successful in the hospital department where the transmission of the ECT-R clone probably emerged, whereas the transmission has continued, despite repeated interventions, in the other hospital departments, and especially at the primary care centres. 
Although the ECT-R clone had not been transmitted to the neighbouring counties in southeast Sweden, a tobramycin-resistant clone predominated by isolates of spa type t084 belonging to CC15 was found in all three counties (Jönköping: $80 \%$, Kalmar: $50 \%$ and Östergötland: $47 \%$ ), and in particular among newborns, suggesting inter-hospital transmission, although this could not be proved with the epidemiological investigation performed in Paper III. However, as in the epidemiological investigation performed in Paper I, this does not necessarily imply that transmissions have not occurred, since some patients may have remained unrecognized for sampling and therefore subsequent genotyping and epidemiological investigation. spa type t084 is one of the most frequently found spa types among MSSA worldwide. In a study from Norway on 1113 MSSA isolates, t084 was shown to be the second most common spa type detected (7.6\%) [152]. Similarly, t084 is the second most abundant MSSA clone causing invasive infections in Europe [153].

The ECT-R clone did not carry the genes encoding PVL, which is the virulence factor most frequently associated with widespread clones of $S$. aureus. Many CA-MRSA strains carry PVL genes, whereas their frequency in MSSA and dominant HA-MRSA clones is much lower [15]. However, a few studies on PVL-positive MSSA have been published [154-157]. The persistence of the ECT-R clone indicates that it is a successful nosocomial clone, which probably possesses other mechanisms of virulence and transmission. The microarray performed in Paper III contained 334 probes targeting 221 distinct genes including antimicrobial resistance, toxins and other virulence markers, which are yet to be analysed. This may give information about the "success-factor" of the ECT-R clone.

This thesis demonstrates that nosocomial transmission is not limited to known resistant pathogens such as MRSA. MSSA strains will develop resistance to antibiotics when conditions of high selective pressure exist, or may be descendants of MRSA, which have partially excised the SCCmec element but maintained resistance to multiple antibiotics other than methicillin. This stresses the need to continuously maintain basic hygiene guidelines and surveillance of antibiotic resistance. As in the case of MRSA, MSSA strains with unusual resistance patterns should be noted in order to prevent nosocomial transmission. 


\subsection{Conclusions}

- The high incidence of multi-resistant MSSA found in Östergötland County was caused by a clonal outbreak of a spa type t002 strain, named the ECT-R clone.

- In addition to erythromycin-, clindamycin- and tobramycin-resistance, moxifloxacinresistance also proved to be characteristic of the ECT-R clone.

- The outbreak of the ECT-R clone was concentrated in eight hospital departments and two primary care centres, all located in the city of Linköping.

- The ECT-R clone carried a pseudo-SCC element, which showed a high resemblance to the SCCmec type II element of the New York/Japan clone (MLST CC5). This suggested probable derivation from a highly successful MRSA strain, which had partially excised its SCCmec.

- Despite a high exchange of patients between the different hospitals in southeast Sweden, the ECT-R clone was limited to Östergötland County.

- A tobramycin-resistant clone predominated by isolates of spa type t084 was found in all three counties in southeast Sweden, and in particular among newborns, suggesting inter-hospital transmission.

- The persistence of the ECT-R clone indicates that there is an insufficiency in the maintenance of basic hygiene guidelines, and that the clone probably possesses mechanisms of virulence and transmission, other than the PVL toxin, that make it so successful. This is yet to be discovered. 


\section{Acknowledgements}

I would like to express my sincere gratitude to all people who have supported me during the work with this thesis. Special thanks to:

\section{Supervisors:}

Anita Hällgren: for excellent support throughout my PhD studies. Thank you for generously sharing your time and for our many discussions. This thesis would not have been completed without your support. I am honoured to have been your $\mathrm{PhD}$ student!

Barbro Isaksson: for believing in me and making my $\mathrm{PhD}$ studies possible, and for sharing your great knowledge in infection control.

Lennart E. Nilsson: for sharing your great knowledge in antibiotics and antibiotic resistance, and for your positive attitude.

\section{Co-workers:}

Anita Johansson: for performing all the searches in the database of the clinical microbiology laboratory at Linköping University Hospital.

Laila Kylinger: for helping me finding my way in the laboratory.

Anna Ryberg: for supporting me with the molecular genotyping methods.

Maria Tärnberg: for many helpful advises and great company during the postgraduate courses. 
Co-authors of the papers: Annika Samuelsson, Carola Grub, Tom Øystein Jonassen, Jonas Swanberg, Annika Wistedt, Robert Skov, Anders Rhod Larsen, Jesper Larsen and Andreas Petersen. Thank you for sharing your knowledge and for critically reviewing the manuscripts.

All other colleagues at the infection control department: for your support and friendship during these years.

Family and friends: for your endless love and support. Now, I am finally finished! 


\section{References}

1. List of prokaryotic names with standing in nomenclature. [cited 20131015]; Available from: http://www.bacterio.cict.fr/.

2. Wilson M. Bacteriology of humans: an ecological perspective. 2008. Malden, MA: Blackwell.

3. Danielsson D. Medicinsk mikrobiologi: infektionsimmunitet. 2002. Stockholm: Liber.

4. Oliveira DC, Tomasz A, de Lencastre H. Secrets of success of a human pathogen: molecular evolution of pandemic clones of meticillin-resistant Staphylococcus aureus. Lancet Infect Dis. 2002; 2(3): p. 180-9.

5. Wertheim HF, et al. The role of nasal carriage in Staphylococcus aureus infections. Lancet Infect Dis. 2005; 5(12): p. 751-62.

6. Kluytmans J, van Belkum A, Verbrugh H. Nasal carriage of Staphylococcus aureus: epidemiology, underlying mechanisms, and associated risks. Clin Microbiol Rev. 1997; 10(3): p. 505-20.

7. Peacock SJ, de Silva I, Lowy FD. What determines nasal carriage of Staphylococcus aureus? Trends Microbiol. 2001; 9(12): p. 605-10.

8. Nouwen J, et al. Human factor in Staphylococcus aureus nasal carriage. Infect Immun . 2004; 72(11): p. 6685-8.

9. Aires de Sousa M, de Lencastre H. Bridges from hospitals to the laboratory: genetic portraits of methicillin-resistant Staphylococcus aureus clones. FEMS Immunol Med Microbiol. 2004; 40(2): p. 101-11.

10. Lowy FD. Staphylococcus aureus infections. N Engl J Med. 1998; 339(8): p. 520-32.

11. Gordon RJ, Lowy FD. Pathogenesis of methicillin-resistant Staphylococcus aureus infection. Clin Infect Dis. 2008; 46 Suppl 5: p. S350-9.

12. Zetola N, et al. Community-acquired meticillin-resistant Staphylococcus aureus: an emerging threat. Lancet Infect Dis. 2005; 5(5): p. 275-86.

13. Voyich JM, et al. Is Panton-Valentine leukocidin the major virulence determinant in community-associated methicillin-resistant Staphylococcus aureus disease? J Infect Dis. 2006; 194(12): p. 1761-70.

14. Gorwitz RJ. Understanding the success of methicillin-resistant Staphylococcus aureus strains causing epidemic disease in the community. J Infect Dis. 2008; 197(2): p. 17982. 
15. Otto M. Community-associated MRSA: what makes them special? Int J Med Microbiol. 2013; 303(6-7): p. 324-30.

16. Greenwood D, Whitley RJ. Modes of action. 8th ed. In: Antibiotic and chemotherapy: anti-infective agents and their use in therapy, ed. Finch RG, et al. 2003; p. 11-24. New York: Churchill Livingstone.

17. Struelens MJ. The problem with resistance. 8th ed. In: Antibiotic and chemotherapy : anti-infective agents and their use in therapy, ed. Finch RG, et al. 2003; p. 25-47. New York: Churchill Livingstone.

18. Weinstein RA. Controlling antimicrobial resistance in hospitals: infection control and use of antibiotics. Emerg Infect Dis. 2001; 7(2): p. 188-92.

19. Canton R, et al. Inappropriate use of antibiotics in hospitals: The complex relationship between antibiotic use and antimicrobial resistance. Enferm Infecc Microbiol Clin. 2013; 31 Suppl 4: p. 3-11.

20. Remesh A, et al. The knowledge, attitude and the perception of prescribers on the rational use of antibiotics and the need for an antibiotic policy-a cross sectional survey in a tertiary care hospital. J Clin Diagn Res. 2013; 7(4): p. 675-9.

21. Magiorakos AP, et al. Multidrug-resistant, extensively drug-resistant and pandrugresistant bacteria: an international expert proposal for interim standard definitions for acquired resistance. Clin Microbiol Infect. 2012; 18(3): p. 268-81.

22. Kahlmeter G. Laboratory control of antimicrobial therapy. 8th ed. In: Antibiotic and chemotherapy : anti-infective agents and their use in therapy, ed. Finch RG, et al. 2003; p. 112-9. New York: Churchill Livingstone.

23. Jones RN. Key considerations in the treatment of complicated staphylococcal infections. Clin Microbiol Infect. 2008; 14 Suppl 2: p. 3-9.

24. Wunderink RG, et al. Linezolid vs vancomycin: analysis of two double-blind studies of patients with methicillin-resistant Staphylococcus aureus nosocomial pneumonia. Chest. 2003; 124(5): p. 1789-97.

25. Yue J, et al. Linezolid versus vancomycin for skin and soft tissue infections. Cochrane Database Syst Rev. 2013; 7: p. CD008056.

26. Georgopapadakou NH. Penicillin-binding proteins and bacterial resistance to betalactams. Antimicrob Agents Chemother. 1993; 37(10): p. 2045-53.

27. Kernodle DS. Mechanisms of resistance to $\beta$-lactam antibiotics. 2nd ed. In: Grampositive pathogens, ed. Fischetti VA, et al. 2006; p. 769-81. Washington DC: ASM Press. 
28. Hackbarth CJ, Chambers HF. blaI and blaR1 regulate beta-lactamase and PBP 2a production in methicillin-resistant Staphylococcus aureus. Antimicrob Agents Chemother. 1993; 37(5): p. 1144-9.

29. Projan SJ, Ruzin A. Antibiotic resistance in the staphylococci. 2nd ed. In: Grampositive pathogens, ed. Fischetti VA, et al. 2006; p. 587-97. Washington DC: ASM Press.

30. Leclercq R. Mechanisms of resistance to macrolides and lincosamides: nature of the resistance elements and their clinical implications. Clin Infect Dis. 2002; 34(4): p. 482-92.

31. Lodder $\mathrm{G}$, et al. Molecular analysis of naturally occuring ermC-encoding plasmids in staphylococci isolated from animals with and without previous contact with macrolide/lincosamide antibiotics. FEMS Immunol Med Microbiol. 1997; 18(1): p. 715.

32. Rochon-Edouard $\mathrm{S}$, et al. In vitro synergistic effects of double and triple combinations of beta-lactams, vancomycin, and netilmicin against methicillin-resistant Staphylococcus aureus strains. Antimicrob Agents Chemother. 2000; 44(11): p. 305560.

33. Boehr DD. Aminoglycosides and aminocyclitols. 8th ed. In: Antibiotic and chemotherapy : anti-infective agents and their use in therapy. ed. Finch RG, et al. 2003; p. 155-84. New York: Churchill Livingstone.

34. Woodford N. Biological counterstrike: antibiotic resistance mechanisms of Grampositive cocci. Clin Microbiol Infect. 2005; 11 Suppl 3: p. 2-21.

35. Peterson LR. Currently available antimicrobial agents and their potential for use as monotherapy. Clin Microbiol Infect. 2008; 14 Suppl 6: p. 30-45.

36. Jevons MP. Celbenin-resistant Staphylococci. BMJ. 1961; 1: p. 124-5.

37. Pinho MG. et al. Complementation of the essential peptidoglycan transpeptidase function of penicillin-binding protein 2 (PBP2) by the drug resistance protein PBP2A in Staphylococcus aureus. J Bacteriol. 2001; 183(22): p. 6525-31.

38. Bush K. $\beta$-lactam antibiotics: penicillins. 8th ed. In: Antibiotic and chemotherapy: anti-infective agents and their use in therapy, ed. Finch RG, et al. 2003; p. 224-58. New York: Churchill Livingstone.

39. Hetem DJ, et al. Nosocomial transmission of community-associated methicillinresistant Staphylococcus aureus in Danish Hospitals. J Antimicrob Chemother. 2012; 67(7): p. 1775-80. 
40. Lindsay JA. Hospital-associated MRSA and antibiotic resistance - What have we learned from genomics? Int J Med Microbiol. 2013; 303(6-7): p. 318-23.

41. Monecke $S$, et al. A field guide to pandemic, epidemic and sporadic clones of methicillin-resistant Staphylococcus aureus. PLoS One. 2011; 6(4): p. e17936.

42. Said-Salim B, Mathema B, Kreiswirth BN. Community-acquired methicillin-resistant Staphylococcus aureus: an emerging pathogen. Infect Control Hosp Epidemiol. 2003; 24(6): p. 451-5.

43. Popovich KJ, Weinstein RA, Hota B. Are community-associated methicillin-resistant Staphylococcus aureus (MRSA) strains replacing traditional nosocomial MRSA strains? Clin Infect Dis. 2008; 46(6): p. 787-94.

44. McCarthy NL, et al. Health care-associated and community-associated methicillinresistant Staphylococcus aureus infections: A comparison of definitions. Am J Infect Control. 2010; 38(8): p. 600-6.

45. Cuny C, Kock R, Witte W. Livestock associated MRSA (LA-MRSA) and its relevance for humans in Germany. Int J Med Microbiol. 2013; 303(6-7): p. 331-7.

46. Nicholson TL, et al. Livestock-Associated Methicillin-Resistant Staphylococcus aureus (LA-MRSA) Isolates of Swine Origin Form Robust Biofilms. PLoS One. 2013; 8(8): p. e73376.

47. Khanna T, et al. Methicillin resistant Staphylococcus aureus colonization in pigs and pig farmers. Vet Microbiol. 2008; 128(3-4): p. 298-303.

48. Garcia-Graells C, et al. Livestock veterinarians at high risk of acquiring methicillinresistant Staphylococcus aureus ST398. Epidemiol Infect. 2012; 140(3): p. 383-9.

49. Smith TC, et al. Methicillin-resistant Staphylococcus aureus in pigs and farm workers on conventional and antibiotic-free swine farms in the USA. PLoS One. 2013; 8(5): p. e63704.

50. Ekkelenkamp MB, et al. [Endocarditis due to meticillin-resistant Staphylococcus aureus originating from pigs]. Ned Tijdschr Geneeskd. 2006; 150(44): p. 2442-7.

51. Rasigade JP, et al. Lethal necrotizing pneumonia caused by an ST398 Staphylococcus aureus strain. Emerg Infect Dis. 2010; 16(8): p. 1330.

52. Lozano C, et al. Empyema caused by MRSA ST398 with atypical resistance profile, Spain. Emerg Infect Dis. 2011; 17(1): p. 138-40.

53. Price LB, et al. Staphylococcus aureus CC398: host adaptation and emergence of methicillin resistance in livestock. MBio. 2012; 3(1). 
54. Garcia-Alvarez L, et al. Meticillin-resistant Staphylococcus aureus with a novel mecA homologue in human and bovine populations in the UK and Denmark: a descriptive study. Lancet Infect Dis. 2011; 11(8): p. 595-603.

55. Shore AC, et al. Detection of staphylococcal cassette chromosome mec type XI carrying highly divergent $m e c A, m e c I, m e c R l, b l a Z$, and $c c r$ genes in human clinical isolates of clonal complex 130 methicillin-resistant Staphylococcus aureus. Antimicrob Agents Chemother. 2011; 55(8): p. 3765-73.

56. Ito T, et al. Guidelines for reporting novel mecA gene homologues. Antimicrob Agents Chemother. 2012; 56(10): p. 4997-9.

57. Petersen A, et al. Epidemiology of methicillin-resistant Staphylococcus aureus carrying the novel mecC gene in Denmark corroborates a zoonotic reservoir with transmission to humans. Clin Microbiol Infect. 2013; 19(1): p. E16-22.

58. Shore AC, Coleman DC. Staphylococcal cassette chromosome mec: Recent advances and new insights. Int J Med Microbiol. 2013; 303(6-7): p. 350-9.

59. Skov R, et al. Phenotypic detection of mecC-MRSA: cefoxitin is more reliable than oxacillin. J Antimicrob Chemother. 2013.

60. Frost LS, et al. Mobile genetic elements: the agents of open source evolution. Nat Rev Microbiol. 2005; 3(9): p. 722-32.

61. Malachowa N, DeLeo FR. Mobile genetic elements of Staphylococcus aureus. Cell Mol Life Sci. 2010; 67(18): p. 3057-71.

62. Morikawa K, et al. A new staphylococcal sigma factor in the conserved gene cassette: functional significance and implication for the evolutionary processes. Genes Cells. 2003; 8(8): p. 699-712.

63. Katayama Y, Ito T, Hiramatsu K. A new class of genetic element, staphylococcus cassette chromosome mec, encodes methicillin resistance in Staphylococcus aureus. Antimicrob Agents Chemother. 2000; 44(6): p. 1549-55.

64. Hiramatsu K, et al. The emergence and evolution of methicillin-resistant Staphylococcus aureus. Trends Microbiol. 2001; 9(10): p. 486-93.

65. Robinson DA, Enright MC. Evolutionary models of the emergence of methicillinresistant Staphylococcus aureus. Antimicrob Agents Chemother. 2003; 47(12): p. 3926-34.

66. Aires de Sousa M, et al. Comparison of genetic backgrounds of methicillin-resistant and -susceptible Staphylococcus aureus isolates from Portuguese hospitals and the community. J Clin Microbiol. 2005; 43(10): p. 5150-7. 
67. IWG-SCC. Classification of staphylococcal cassette chromosome mec (SCCmec): guidelines for reporting novel SCCmec elements. Antimicrob Agents Chemother. 2009; 53(12): p. 4961-7.

68. Couto I, et al. Ubiquitous presence of a mecA homologue in natural isolates of Staphylococcus sciuri. Microb Drug Resist. 1996; 2(4): p. 377-91.

69. Wu S, de Lencastre $\mathrm{H}$, Tomasz A. Genetic organization of the mecA region in methicillin-susceptible and methicillin-resistant strains of Staphylococcus sciuri. J Bacteriol. 1998; 180(2): p. 236-42.

70. Tsubakishita $\mathrm{S}$, et al. Origin and molecular evolution of the determinant of methicillin resistance in staphylococci. Antimicrob Agents Chemother. 2010; 54(10): p. 4352-9.

71. Boundy S, et al. Characterization of the Staphylococcus aureus rRNA methyltransferase encoded by $\operatorname{orf} X$, the gene containing the staphylococcal chromosome Cassette mec (SCCmec) insertion site. J Biol Chem. 2013; 288(1): p. $132-40$.

72. International Working Group on the Staphylococcal Cassette Chromosome elements. [cited 20131115]; Available from: http://www.sccmec.org/.

73. Deurenberg RH, Stobberingh EE. The evolution of Staphylococcus aureus. Infect Genet Evol. 2008; 8(6): p. 747-63.

74. Lee SM, et al. Fitness cost of staphylococcal cassette chromosome mec in methicillinresistant Staphylococcus aureus by way of continuous culture. Antimicrob Agents Chemother. 2007; 51(4): p. 1497-9.

75. Donnio PY, et al. Partial excision of the chromosomal cassette containing the methicillin resistance determinant results in methicillin-susceptible Staphylococcus aureus. J Clin Microbiol. 2005; 43(8): p. 4191-3.

76. Donnio PY, et al. Molecular and epidemiological evidence for spread of multiresistant methicillin-susceptible Staphylococcus aureus strains in hospitals. Antimicrob Agents Chemother. 2007; 51(12): p. 4342-50.

77. Shore AC, et al. Detection of staphylococcal cassette chromosome mec-associated DNA segments in multiresistant methicillin-susceptible Staphylococcus aureus (MSSA) and identification of Staphylococcus epidermidis ccrAB4 in both methicillinresistant S. aureus and MSSA. Antimicrob Agents Chemother. 2008; 52(12): p. 440719. 
78. Oliveira DC, de Lencastre H. Multiplex PCR strategy for rapid identification of structural types and variants of the mec element in methicillin-resistant Staphylococcus aureus. Antimicrob Agents Chemother. 2002; 46(7): p. 2155-61.

79. Ito T, et al. Insights on antibiotic resistance of Staphylococcus aureus from its whole genome: genomic island SCC. Drug Resist Updat. 2003; 6(1): p. 41-52.

80. Ito $\mathrm{T}$, et al. Novel type $\mathrm{V}$ staphylococcal cassette chromosome mec driven by a novel cassette chromosome recombinase, ccrC. Antimicrob Agents Chemother. 2004; 48(7): p. 2637-51.

81. Johnson AP, Pearson A, Duckworth G. Surveillance and epidemiology of MRSA bacteraemia in the UK. J Antimicrob Chemother. 2005; 56(3): p. 455-62.

82. Kluytmans-Vandenbergh MF, Kluytmans JA. Community-acquired methicillinresistant Staphylococcus aureus: current perspectives. Clin Microbiol Infect. 2006; 12 Suppl 1: p. 9-15.

83. Milheirico C, Oliveira DC, de Lencastre H. Multiplex PCR strategy for subtyping the staphylococcal cassette chromosome mec type IV in methicillin-resistant Staphylococcus aureus: 'SCCmec IV multiplex'. J Antimicrob Chemother. 2007; 60(1): p. $42-8$.

84. Smyth DS, Wong A, Robinson DA. Cross-species spread of SCCmec IV subtypes in staphylococci. Infect Genet Evol. 2011; 11(2): p. 446-53.

85. Emori TG, Gaynes RP. An overview of nosocomial infections, including the role of the microbiology laboratory. Clin Microbiol Rev. 1993; 6(4): p. 428-42.

86. Horan TC, Andrus M, Dudeck MA. CDC/NHSN surveillance definition of health care-associated infection and criteria for specific types of infections in the acute care setting. Am J Infect Control. 2008; 36(5): p. 309-32.

87. Kaoutar B, et al. Nosocomial infections and hospital mortality: a multicentre epidemiology study. J Hosp Infect. 2004; 58(4): p. 268-75.

88. Jarvis WR. Usefulness of molecular epidemiology for outbreak investigations. Infect Control Hosp Epidemiol. 1994; 15(7): p. 500-3.

89. Beck-Sague C, Jarvis W, Martone WJ. Outbreak investigations. Infect Control Hosp Epidemiol. 1997; 18(2): p. 138-45.

90. Eveillard M, et al. Association between hospital-acquired infections and patients' transfers. Infect Control Hosp Epidemiol. 2001; 22(11): p. 693-6.

91. Huang SS, et al. Quantifying interhospital patient sharing as a mechanism for infectious disease spread. Infect Control Hosp Epidemiol. 2010; 31(11): p. 1160-9. 
92. Karkada UH, et al. Limiting the spread of highly resistant hospital-acquired microorganisms via critical care transfers: a simulation study. Intensive Care Med. 2011; 37(10): p. 1633-40.

93. Donker T, et al. Hospital networks and the dispersal of hospital-acquired pathogens by patient transfer. PLoS One. 2012; 7(4): p. e35002.

94. Donker T, Wallinga J, Grundmann H. Dispersal of antibiotic-resistant high-risk clones by hospital networks: changing the patient direction can make all the difference. $J$ Hosp Infect. 2013.

95. Safdar N, Maki DG. The commonality of risk factors for nosocomial colonization and infection with antimicrobial-resistant Staphylococcus aureus, enterococcus, gramnegative bacilli, Clostridium difficile, and Candida. Ann Intern Med. 2002; 136(11): p. 834-44.

96. Oztoprak N, et al. Risk factors for ICU-acquired methicillin-resistant Staphylococcus aureus infections. Am J Infect Control. 2006; 34(1): p. 1-5.

97. Henderson DK. Managing methicillin-resistant staphylococci: a paradigm for preventing nosocomial transmission of resistant organisms. Am J Infect Control. 2006; 34(5 Suppl 1): p. S46-54: discussion S64-73.

98. Upshaw-Owens M, Bailey CA. Preventing hospital-associated infection: MRSA. Medsurg Nurs. 2012; 21(2): p. 77-81.

99. Reingold AL. Outbreak investigations - a perspective. Emerg Infect Dis. 1998; 4(1): p. 21-7.

100. Andrei A, Zervos MJ. The application of molecular techniques to the study of hospital infection. Arch Pathol Lab Med. 2006; 130(5): p. 662-8.

101. Tenover FC, et al. Interpreting chromosomal DNA restriction patterns produced by pulsed-field gel electrophoresis: criteria for bacterial strain typing. J Clin Microbiol. 1995; 33(9): p. 2233-9.

102. Tenover FC, Arbeit RD, Goering RV. How to select and interpret molecular strain typing methods for epidemiological studies of bacterial infections: a review for healthcare epidemiologists. Molecular Typing Working Group of the Society for Healthcare Epidemiology of America. Infect Control Hosp Epidemiol. 1997; 18(6): p. 426-39.

103. Schwartz DC, Cantor CR. Separation of yeast chromosome-sized DNAs by pulsed field gradient gel electrophoresis. Cell. 1984; 37(1): p. 67-75. 
104. Sabat AJ, et al. Overview of molecular typing methods for outbreak detection and epidemiological surveillance. Euro Surveill. 2013; 18(4): p. 20380.

105. Deurenberg RH, et al. The molecular evolution of methicillin-resistant Staphylococcus aureus. Clin Microbiol Infect. 2007; 13(3): p. 222-35.

106. Frenay HM, et al. Molecular typing of methicillin-resistant Staphylococcus aureus on the basis of protein A gene polymorphism. Eur J Clin Microbiol Infect Dis. 1996; 15(1): p. 60-4.

107. Shopsin B, et al. Evaluation of protein A gene polymorphic region DNA sequencing for typing of Staphylococcus aureus strains. J Clin Microbiol. 1999; 37(11): p. 355663.

108. Monecke S, Slickers P, Ehricht R. Assignment of Staphylococcus aureus isolates to clonal complexes based on microarray analysis and pattern recognition. FEMS Immunol Med Microbiol. 2008; 53(2): p. 237-51.

109. Diep BA, Perdreau-Remington F, Sensabaugh GF. Clonal characterization of Staphylococcus aureus by multilocus restriction fragment typing, a rapid screening approach for molecular epidemiology. J Clin Microbiol. 2003; 41(10): p. 4559-64.

110. Hallin M, et al. Validation of pulsed-field gel electrophoresis and spa typing for longterm, nationwide epidemiological surveillance studies of Staphylococcus aureus infections. J Clin Microbiol. 2007; 45(1): p. 127-33.

111. Mullis K, et al. Specific enzymatic amplification of DNA in vitro: the polymerase chain reaction. Cold Spring Harb Symp Quant Biol. 1986; 51 Pt 1: p. 263-73.

112. Powledge TM. The polymerase chain reaction. Adv Physiol Educ. 2004; 28(1-4): p. 44-50.

113. Heid CA, et al. Real time quantitative PCR. Genome Res. 1996; 6(10): p. 986-94.

114. Sanger F, Nicklen S, Coulson AR. DNA sequencing with chain-terminating inhibitors. Proc Natl Acad Sci U S A. 1977; 74(12): p. 5463-7.

115. Ronaghi M, Uhlen M, Nyren P. A sequencing method based on real-time pyrophosphate. Science. 1998; 281(5375): p. 363, 365.

116. Mardis ER. Next-generation DNA sequencing methods. Annual Review of Genomics and Human Genetics. 2008; 9: p. 387-402.

117. Johnsson D, et al. Detection of Panton-Valentine leukocidin gene in Staphylococcus aureus by LightCycler PCR: clinical and epidemiological aspects. Clin Microbiol Infect. 2004; 10(10): p. 884-9. 
118. Huletsky A, et al. New real-time PCR assay for rapid detection of methicillin-resistant Staphylococcus aureus directly from specimens containing a mixture of staphylococci. J Clin Microbiol. 2004; 42(5): p. 1875-84.

119. Lin MF, Huang ML, Lai SH. Investigation of a pyoderma outbreak caused by methicillin-susceptible Staphylococcus aureus in a nursery for newborns. J Hosp Infect. 2004; 57(1): p. 38-43.

120. Grub C, et al. A multidrug-resistant, methicillin-susceptible strain of Staphylococcus aureus from a neonatal intensive care unit in Oslo, Norway. Scand J Infect Dis. 2010; 42(2): p. 148-51.

121. Boers SA, et al. An outbreak of a multiresistant methicillin-susceptible Staphylococcus aureus (MR-MSSA) strain in a burn centre: the importance of routine molecular typing. Burns. 2011; 37(5): p. 808-13.

122. McDougal LK, et al. Pulsed-field gel electrophoresis typing of oxacillin-resistant Staphylococcus aureus isolates from the United States: establishing a national database. J Clin Microbiol. 2003; 41(11): p. 5113-20.

123. Hallin M, et al. Genetic relatedness between methicillin-susceptible and methicillinresistant Staphylococcus aureus: results of a national survey. J Antimicrob Chemother. 2007; 59(3): p. 465-72.

124. Petersson AC, et al. Evaluating the usefulness of spa typing, in comparison with pulsed-field gel electrophoresis, for epidemiological typing of methicillin-resistant Staphylococcus aureus in a low-prevalence region in Sweden 2000-2004. Clin Microbiol Infect. 2010; 16(5): p. 456-62.

125. Larsson AK, et al. Epidemiology of MRSA in southern Sweden: strong relation to foreign country of origin, health care abroad and foreign travel. Eur J Clin Microbiol Infect Dis. 2013.

126. Ito T, et al. Structural comparison of three types of staphylococcal cassette chromosome mec integrated in the chromosome in methicillin-resistant Staphylococcus aureus. Antimicrob Agents Chemother. 2001; 45(5): p. 1323-36.

127. Okuma K, et al. Dissemination of new methicillin-resistant Staphylococcus aureus clones in the community. J Clin Microbiol. 2002; 40(11): p. 4289-94.

128. Francois P, et al. A novel multiplex real-time PCR assay for rapid typing of major staphylococcal cassette chromosome mec elements. J Clin Microbiol. 2004; 42(7): p. 3309-12. 
129. Zhang K, et al. Novel multiplex PCR assay for characterization and concomitant subtyping of staphylococcal cassette chromosome mec types I to V in methicillinresistant Staphylococcus aureus. J Clin Microbiol. 2005; 43(10): p. 5026-33.

130. Desjardins M, et al. Evaluation of the IDI-MRSA assay for detection of methicillinresistant Staphylococcus aureus from nasal and rectal specimens pooled in a selective broth. J Clin Microbiol. 2006; 44(4): p. 1219-23.

131. Blanc DS, et al. High proportion of wrongly identified methicillin-resistant Staphylococcus aureus carriers by use of a rapid commercial PCR assay due to presence of staphylococcal cassette chromosome element lacking the mecA gene. $J$ Clin Microbiol. 2011; 49(2): p. 722-4.

132. Stamper PD, et al. Genotypic and phenotypic characterization of methicillinsusceptible Staphylococcus aureus isolates misidentified as methicillin-resistant Staphylococcus aureus by the BD GeneOhm MRSA assay. J Clin Microbiol. 2011; 49(4): p. 1240-4.

133. Bartels MD, et al. A common variant of staphylococcal cassette chromosome mec type IVa in isolates from Copenhagen, Denmark, is not detected by the BD GeneOhm methicillin-resistant Staphylococcus aureus assay. J Clin Microbiol. 2009; 47(5): p. 1524-7.

134. Kuroda M, et al. Whole genome sequencing of meticillin-resistant Staphylococcus aureus. Lancet. 2001; 357(9264): p. 1225-40.

135. Wong H, et al. Characterization of Staphylococcus aureus isolates with a partial or complete absence of staphylococcal cassette chromosome elements. J Clin Microbiol. 2010; 48(10): p. 3525-31.

136. Corkill JE, et al. Detection of elements of the staphylococcal cassette chromosome (SCC) in a methicillin-susceptible ( $m e c A$ gene negative) homologue of a fucidinresistant MRSA. J Antimicrob Chemother. 2004; 54(1): p. 229-31.

137. Boundy S, et al. Spontaneous staphylococcal cassette chromosome mec element excision in Staphylococcus aureus nasal carriers. J Clin Microbiol. 2012; 50(2): p. 469-71.

138. Grubb WB, Annear DI. Spontaneous loss of methicillin resistance in Staphylococcus aureus at room-temperature. Lancet. 1972; 2(7789): p. 1257.

139. Deplano A, et al. In vivo deletion of the methicillin resistance mec region from the chromosome of Staphylococcus aureus strains. J Antimicrob Chemother. 2000; 46(4): p. $617-20$. 
140. Noto MJ, Fox PM, Archer GL. Spontaneous deletion of the methicillin resistance determinant, mecA, partially compensates for the fitness cost associated with highlevel vancomycin resistance in Staphylococcus aureus. Antimicrobial Agents and Chemotherapy. 2008; 52(4): p. 1221-1229.

141. Inglis B, Matthews PR, Stewart PR. Induced Deletions within a Cluster of Resistance Genes in the Mec Region of the Chromosome of Staphylococcus-Aureus. Journal of General Microbiology. 1990; 136: p. 2231-2239.

142. Poston SM, Li Saw Hee FL. Genetic characterisation of resistance to metal ions in methicillin-resistant Staphylococcus aureus: elimination of resistance to cadmium, mercury and tetracycline with loss of methicillin resistance. J Med Microbiol. 1991; 34(4): p. 193-201.

143. Limbago B, et al. Characterization of methicillin-resistant Staphylococcus aureus isolates collected in 2005 and 2006 from patients with invasive disease: a populationbased analysis. J Clin Microbiol. 2009; 47(5): p. 1344-51.

144. Budimir A, et al. A variant of the Southern German clone of methicillin-resistant Staphylococcus aureus is predominant in Croatia. Clin Microbiol Infect. 2010; 16(8): p. $1077-83$.

145. Knight GM, et al. Shift in dominant hospital-associated methicillin-resistant Staphylococcus aureus (HA-MRSA) clones over time. J Antimicrob Chemother. 2012; 67(10): p. 2514-22.

146. Charbonneau P, et al. Fluoroquinolone use and methicillin-resistant Staphylococcus aureus isolation rates in hospitalized patients: a quasi experimental study. Clin Infect Dis. 2006; 42(6): p. 778-84.

147. Tacconelli E, et al. Does antibiotic exposure increase the risk of methicillin-resistant Staphylococcus aureus (MRSA) isolation? A systematic review and meta-analysis. $J$ Antimicrob Chemother. 2008; 61(1): p. 26-38.

148. Cook PP, et al. Sustained reduction in antimicrobial use and decrease in methicillinresistant Staphylococcus aureus and Clostridium difficile infections following implementation of an electronic medical record at a tertiary-care teaching hospital. $J$ Antimicrob Chemother. 2011; 66(1): p. 205-9.

149. Parienti JJ, et al. Hospital-wide modification of fluoroquinolone policy and meticillinresistant Staphylococcus aureus rates: a 10-year interrupted time-series analysis. J Hosp Infect. 2011; 78(2): p. 118-22. 
150. den Heijer CDJ, et al. Prevalence and resistance of commensal Staphylococcus aureus, including methicillin-resistant $S$. aureus, in nine European countries: a cross-sectional study. Lancet Infect Dis. 2013; 13: p. 409-15.

151. Donker T, Wallinga J, Grundmann H. Patient referral patterns and the spread of hospital-acquired infections through national health care networks. PLoS Comput Biol 2010; 6(3): p. e1000715.

152. Sangvik M, et al. Age- and gender-associated Staphylococcus aureus spa types found among nasal carriers in a general population: the Tromso Staph and Skin Study. J Clin Microbiol. 2011; 49(12): p. 4213-8.

153. Grundmann H, et al. Geographic distribution of Staphylococcus aureus causing invasive infections in Europe: a molecular-epidemiological analysis. PLoS Med. 2010; 7(1): p. e1000215.

154. Monecke S, et al. High diversity of Panton-Valentine leukocidin-positive, methicillinsusceptible isolates of Staphylococcus aureus and implications for the evolution of community-associated methicillin-resistant S. aureus. Clin Microbiol Infect. 2007; 13(12): p. 1157-64.

155. Muttaiyah S, et al. Incidence, risk factors, and outcomes of Panton-Valentine leukocidin-positive methicillin-susceptible Staphylococcus aureus infections in Auckland, New Zealand. J Clin Microbiol. 2010; 48(10): p. 3470-4.

156. Chiu YK, Lo WT, Wang CC. Risk factors and molecular analysis of Panton-Valentine leukocidin-positive methicillin-susceptible Staphylococcus aureus colonization and infection in children. J Microbiol Immunol Infect. 2012; 45(3): p. 208-13.

157. AlFouzan W, et al. Frequency and clinical association of Panton-Valentine leukocidinpositive Staphylococcus aureus isolates: a study from Kuwait. Med Princ Pract. 2013; 22(3): p. 245-9. 



\section{Papers}

The articles associated with this thesis have been removed for copyright reasons. For more details about these see:

http://urn.kb.se/resolve?urn=urn:nbn:se:liu:diva-103679 